\title{
THE RELATION OF PREGNANCY AND CHILDBIRTH TO PELLAGRA IN WOMEN *
}

\author{
J. F. SILER, M.D. \\ P. E. GARRISON, M.D. \\ Major, Medical Corps, U. S. Army Passed Asst. Surg., U. S. Navy \\ AND \\ W. J. MACNEAL, M.D. \\ NEW YORK
}

\section{INTRODUCTION}

The exceptionally high prevalence of pellagra among women between the ages of 20 and 45 years has been pointed out in previous publications of this commission and is now generally recognized as characteristic of pellagra in the general population of the southern portion of the United States. In our First Progress Report ${ }^{1}$ attention was directed to the observation that pregnancy seems to inhibit the development of pellagrous symptoms, and to the indication that childbirth $^{2}$ seems to predispose to an attack of the disease. In the present paper we wish to examine the correlation between the attack of pellagra, either initial or recurrent, on the one hand, and the existence of pregnancy and the event of childbirth on the other, in the histories of all the pellagrins in our series for whom there are definite records in regard to these phenomena.

\section{INITIAL ATTACK OF PELLAGRA DURING PREGNANCY}

In the histories of 624 women of childbearing age who suffered their first attack of pellagra in a year prior to 1915 there are twenty definite records of onset of pellagra during pregnancy. For the 101 colored women counted in this group there are no such instances recorded. Excluding the 101 colored women from the present consideration, we find that for twenty, or 3.8 per cent., of the remaining

\footnotetext{
* Submitted for publication Aug. 10, 1916.

* From the Robert M. Thompson Pellagra Commission of the New York Post-Graduate Medical School and Hospital.

* This paper has been written since Dr. Garrison and Dr. Siler were recalled to active duty in the Medical Corps, U. S. Navy, and the Medical Corps, U. S. Army, respectively. They are not personally responsible for the detailed compilation of data or for the specific deductions drawn from them.

1. Siler, J. F., and Garrison, P. E.: An Intensive Study of the Epidemiology of Pellagra, Am. Jour. Med. Sc., 1913, 146, 42, 238; First Progress Report of the Thompson-McFadden Pellagra Commission, 1914, p. 17.

2. Siler, J. F.; Garrison, P. E., and MacNeal, W. J.: Pellagra, a Summary of the First Progress Report of the Thompson-McFadden Pellagra Commission, Jour. Am. Med. Assn., 1914, 62, 8; First Progress Report, 1914, p. 3.
} 


\section{3 white women there is history of onset of pellagra during pregnancy. Brief notes for each of these cases follow.}

Pellagrin 186, aged 22 at onset of pellagra in March, 1908, was in the second month of pregnancy when she suffered an initial attack of pellagra, manifested by scaling of the hands, stomatitis and diarrhea. The eruption subsided in about two weeks and the attack was evidently a mild one. During the following two years this patient remained entirely free from the disease, again becoming pregnant in August, 1909, and giving birth to a child in May, 1910. In April, 1911, and again in 1912 she suffered mild recurrences of pellagra, but remained free from symptoms of the disease in 1913 and 1914.

Pellagrin 277, aged 25 at the time of onset, first developed a pellagrous erythema in April, 1908, three months before the birth of her child. The attack was evidentiy mild, although complete, showing erythema of hands, sore mouth, dysentery and nervous symptoms. The eruption remained for about one week, and by winter there was a complete subsidence of all symptoms. In April, 1909, she again had a mild, though complete, attack. There was a very severe recurrence in March, 1910, during which the patient was bedridden for six weeks. In the following two years mild recurrences appeared in April and June, respectively. During 1913 and 1914 this patient remained entirely free from symptoms of pellagra.

Pellagrin 644, aged 26 at onset, was in the fourth month of pregnancy when pellagra first developed in April, 1909. The attack was mild, consisting of sore mouth, followed by an erythema, which subsided in two months. During the following three years she remained free from the disease, being pregnant through the entire pellagra season in 1911. In 1913 she suffered her first recurrence and it was a mild one. In 1914 she remained free from symptoms of pellagra.

Pellagrin 827, aged 33 at onset, was in the seventh month of pregnancy when pellagrous symptoms first developed in August, 1909. The attack was undoubtedly a severe one, for after the birth of her child in October, 1909, the patient was admitted to a hospital, where she died six weeks later.

Pellagrin 95, aged 26 at onset, was in the third or fourth month of pregnancy when she suffered an initial attack of pellagra about May, 1910. The attack was manifested merely by characteristic erythema on the hands. In May, 1911, the patient suffered a mild recurrence, with sore mouth and an erythema on the hands and arms, which subsided in about one week. During the winter of 1911 and also in 1912 she had some mental derangement, but had shown no further recurrence of erythema to July, 1912, the date of the last observation.

Pellagrin 18, aged 29 at the time of onset, developed an initial attack of pellagra in June, 1910, before the birth of her child, the exact date of delivery being unrecorded. The attack was mild, manifested by erythema on the forearms, sore mouth and dysentery, all of which symptoms subsided by July, 1910 . In May, 1911, she suffered a severe recurrence with skin, gastro-intestinal and nervous symptoms, which persisted until the following September. Again in April, 1912, this patient had a complete recurrence of pellagra, which had no definite subsidence that year, but ended in death in January, 1913.

Pellagrin 62, aged 21 at onset, was in the fourth month of pregnancy when she first developed an erythema in July, 1911. The attack seems to have been rather severe, with sore mouth, an intermittent diarrhea and an eruption which lasted through most of the summer. In this case there was history of ill health following an operation for pelvic disease in 1909. Early in January, 1912, the patient gave birth to a child and in June, 1912, she suffered a mild recurrence, having been troubled all the spring with diarrhea and insomnia. In the summer of 1913 she had a pronounced attack while pregnant, giving birth to a child in October. In 1914 she is recorded as having recurrences of erythema 
in February, May and August, suffering also from sore mouth, insomnia, constipation and loss of appetite during the attack in May.

Pellagrin 568, aged 23 at the time of onset, was in the ninth month of pregnancy when an initial erythema appeared in June, 1911. The patient suffered also from diarrhea, but within two months after the birth of the child the symptoms subsided. After the first attack in 1911 this patient remained quite free from the disease up to the date of our last observation, July, 1914.

Pellagrin 724, aged 24 at onset, suffered her first attack of pellagra in the fall of 1911, when in the first month of pregnancy. The attack consisted merely of the eruption on the hands, which subsided before winter. In June, 1912, after the birth of her child, the patient suffered a recurrence of erythema. She is without record for 1913, but is reported to have suffered a recurrence of erythema in the spring of 1914.

Pellagrin 280, aged 19 at the time of onset, became pregnant the first week in July, 1912, and suffered her initial attack of pellagra in that same month. The only symptom in this first attack was the erythema, which appeared on her hands and subsided by fall. In July, 1913, just three months after childbirth, she suffered a recurrence of pellagra, with erythema, stomatitis, diarrhea and sore tongue. In May, 1914, she had a recurrence of the skin symptoms and sore motth.

Pellagrin 260, aged 22 at onset, was in the sixth month of pregnancy, when a pellagrous erythema first developed in April, 1912. Her child was born in August, 1912. In this case there were repeated exacerbations of the cutaneous eruption and persistent weakness throughout the fall and winter. She became worse in the summer of 1913. She was admitted to the hospital in Spartanburg and died there Sept. 7, 1913.

Pellagrin 531, aged 29 at the time of onset, was in the second month of pregnancy when she developed an initial attack of pellagra in August, 1912. At this time she had merely a slight erythema. After the birth of her child in March, 1913, she had a recurrence, beginning in May, manifested by erythema, sore tongue and dysentery. In 1914 she reported better health than she had had for years, and she remained free from symptoms during that year.

Pellagrin 701, aged 31 at onset, was in the eighth month of pregnancy when an erythema first appeared on her hands in March, 1912. The attack was a very slight one, evidenced merely by the pellagrous eruption. In the spring of 1913 she had a severe recurrence. In May, 1914, she suffered a recurrence of the skin eruption.

Pellagrin 253, aged 35 at onset, was in the eighth month of pregnancy when a pellagrous erythema first developed in May, 1912. The eruption, which was the only symptom in this initial attack, extended over the hands and forearms and subsided by August, 1912. The patient remained quite free from recurrence of the disease in 1913 and 1914.

Pellagrin 1167, aged 21 at onset, suffered an initial attack of pellagra in July, 1913 , just one month before the birth of a child. The only symptom in this first attack was the typical erythema, which cleared up after her child was born. In May, 1914, she had a recurrence of the erythema.

Pellagrin 977, aged 22 at the time of onset, was in the eighth month of pregnancy when the initial erythema appeared in July, 1914. The symptoms consisted of eruption on the forearms and hands, with sore mouth and indigestion.

Pellagrin 1267, aged 28 at the time of onset, suffered her initial attack of pellagra a few days before the birth of her child in January, 1914. This attack was manifested by gastro-intestinal as well as skin symptoms, and these did not disappear until some time after the birth of the child.

Pellagrin 958, aged 29 at onset, had suffered indigestion for two months prior to the development of pellagra in February, 1914, three months before the birth of her child. In this case there was an early subsidence of skin symptoms, but diarrhea persisted to the date of last observation in July, 1914.

Pellagrin 1078, aged 42 at the time of onset, was well advanced in pregnancy 
when pellagra first developed in the latter part of July, 1914. With the exception of the erythema, which recurred that summer, and sore mouth, the patient's health was not markedly impaired.

Pellagrin 964, age not recorded, suffered a first attack of pellagra in January, 1914 , just before the birth of her child. The onset was mild, but in the following June the erythema recurred and with it stomatitis and marked general weakness.

TABle 1.-Summary of the Twenty Initial Attacks of Pellagra Which Occurred During Pregsincy

\begin{tabular}{|c|c|c|c|c|c|}
\hline $\begin{array}{l}\text { Pellagrin } \\
\text { Number } \\
\text { - }\end{array}$ & $\begin{array}{c}\text { Age at } \\
\text { Onset }\end{array}$ & $\begin{array}{c}\text { Date of } \\
\text { Onset }\end{array}$ & $\begin{array}{l}\text { Month of } \\
\text { Pregnancy }\end{array}$ & $\begin{array}{c}\text { Character of } \\
\text { Attack }\end{array}$ & $\begin{array}{c}\text { History During } \\
\text { Pregnancy }\end{array}$ \\
\hline 186 & 22 & March, 1908 & Second & Mild & Recovery \\
\hline 277 & 25 & April, 1908 & Sixth & Mild & Recovery \\
\hline 644 & 26 & April, 1909 & Fourth & Mild & Recovery \\
\hline 827 & 33 & August, 1909 & Seventh & Severe & Persisted* \\
\hline 95 & 26 & May, 1910 & Third or Fourth & Mild & Recovery \\
\hline 18 & 29 & June, 1910 & Miđdle & Mild & Recovery \\
\hline 62 & 21 & July, 1911 & Fourth & Severe & Recovery \\
\hline 568 & 23 & June, 1911 & Ninth & Mild & Recovery \\
\hline 724 & 24 & Fall, 1911 & First & Mild & Recovery \\
\hline 280 & 19 & July, 1912 & First & Mild & Recovery \\
\hline 260 & 22 & April, 1912 & Sixth & Severe & Persisted $\dagger$ \\
\hline 531 & 29 & August, 1912 & Second & Mild & Recovery \\
\hline 701 & 31 & March, 1912 & Eighth & Slight & Recovery \\
\hline 253 & 35 & May, 1912 & Eighth & Mild & Recovery \\
\hline 1167 & 21 & July, 1913 & Eighth & Mild & Recovery \\
\hline 977 & 22 & July, 1914 & Eighth & Mild & Recovery \\
\hline 1267 & 28 & January, 1914 & Nintb & Mild & Recovery \\
\hline 958 & 29 & February, 1914 & Sixth & Mild & Recovery \\
\hline 1078 & 42 & July, 1914 & "Advanced" & Mild & Recovery \\
\hline 964 & $\begin{array}{l}\text { Not re- } \\
\text { corded }\end{array}$ & January, 1914 & Ninth & Mild & Recovery \\
\hline
\end{tabular}

* This patient died of pellagra six weeks after childbirth in the fall of 1909 .

+ This patient survived the year, giving birth to her child in August, 1912. She did not regain her health, but continued to suffer from pellagra until death in September, 1913.

Among the 523 recorded initial attacks of pellagra in white women in the age period 12 to 49 years there are only twenty, or 3.8 per cent., in which the onset occurred during pregnancy. None of these twenty died of pellagra during pregnancy. In fact, with a single exception, those who developed the disease early in pregnancy suffered only mild attacks. This exceptional case, Pellagrin 62, had been in ill health following a pelvic operation in 1909 and she suffered a rather severe initial attack of pellagra in July, 1911, in the fourth month of pregnancy. In one instance, Pellagrin 827, the attack appeared in the seventh month of pregnancy, persisted until childbirth and ended in 
death six weeks later. In another case, Pellagrin 260, pellagra appeared in the sixth month of pregnancy and persisted until long after delivery, the patient dying of pellagra in the following year. The comparative infrequency ${ }^{3}$ of onset of pellagra during pregnancy and the benign character of the attack when it does occur indicate that during pregnancy there is an increased resistance to pellagra.

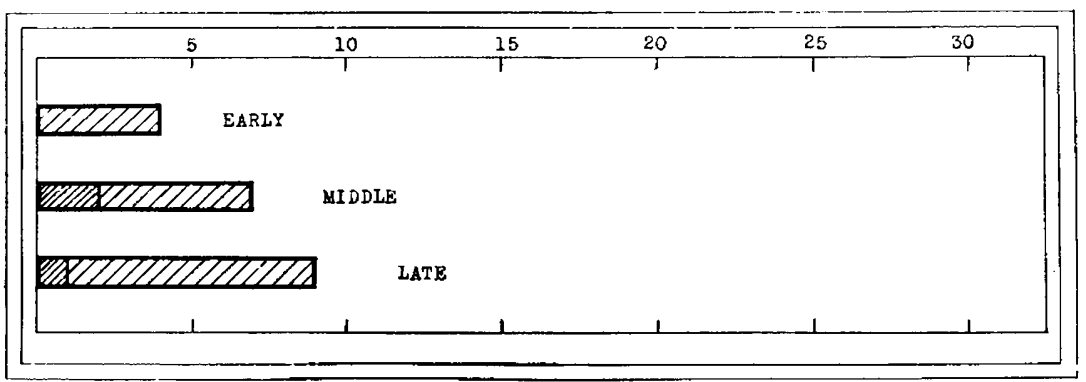

Fig. 1.- Initial attacks of pellagra which began during the first, second and last three months of pregnancy, respectively. The total length of the bar indicates the number of instances of onset in the respective three-month period. The more thickly shaded portion indicates the number of instances in which the attack of pellagra was severe.

\section{THE RELATION OF CHILDBIRTH TO INITIAL ATTACK}

Frequently in the histories of pellagrous women childbirth just previous to the initial attack is recorded as a possible predisposing factor. On closer examination of the records of these mothers the rather large number of instances in which a childbirth in the early part of the year, usually from January to April, has been followed within a few months, or even weeks, by an initial development of pellagrous symptoms invites consideration. In the records of the 624 pellagrous women of childbearing age ( 12 to 49 years) in our series to the end of 1914 there are fifty-seven who gave a history of childbirth within six months preceding onset. This group of 624 women includes 101 colored pellagrins. Because of the comparatively small number of records for the colored race and doubtless, also, because of the incompleteness of the records, there are recorded but four cases of possible predisposing childbirth, or 4 per cent., for the colored race. After subtracting from the total group of women the 101 colored pellagrins,

3. The condition of pregnancy exists at any given time in more than 3.8 per cent. of the women between 12 and 49 years of age in this population. If only 3.8 per cent: of them were pregnant at a given time on the average, then the average woman would be pregnant 3.8 per cent. of 38 years ( 12 to 49 , inclusive), or 1.44 years, about seventeen months, and would, therefore, fail to bring forth more than two children during her childbearing period, a number too small to maintain the population and unquestionably far below the actual average number in this population. 
we find that fifty-three, or 10.1 per cent., of the remaining 523 white women suffered onset of pellagra following a childbirth.

If the total birth records in Spartanburg County for a given year were available for comparison with the total number of initial attacks of pellagra among mothers delivered in the respective year, it would be highly interesting to ascertain in what ratio women who had recently borne a child were attacked by this disease. We have, however, the histories of the 523 white women who did suffer attack. The fact that a very large proportion of all women in these southern mill villages do bear children and that standards of living and environmental influences are generally similar reduces them to a fairly uniform basis for comparison.

TABLE 2.-CoMPARISON OF THE NUMBER OF WOMEN FROM 12 To 49 YEARS of Age, with Onset of Pellagra in Each Year, with the Number Having Record of Childbirth Just Prior to Onset of the Disease

\begin{tabular}{|c|c|c|c|c|c|c|}
\hline \multirow{3}{*}{ Year of Onset } & \multicolumn{3}{|c|}{ White Women } & \multicolumn{3}{|c|}{ Colored Women } \\
\hline & \multirow{2}{*}{$\begin{array}{c}\text { Total } \\
\text { Initial } \\
\text { Attacks }\end{array}$} & \multicolumn{2}{|c|}{$\begin{array}{l}\text { Instances of } \\
\text { Childbirth Just } \\
\text { Prior to Onset }\end{array}$} & \multirow{2}{*}{$\begin{array}{c}\text { Total } \\
\text { Initial } \\
\text { Attacks }\end{array}$} & \multicolumn{2}{|c|}{$\begin{array}{l}\text { Instances of } \\
\text { Childbirth Just } \\
\text { Prior to Onset }\end{array}$} \\
\hline & & Number & Per Cent. & & Number & Per Cent. \\
\hline Before $1908 \ldots \ldots \ldots \ldots \ldots \ldots \ldots$ & 28 & 3 & 10.7 & 4 & 0 & 0.0 \\
\hline $1908 \ldots \ldots \ldots \ldots \ldots \ldots \ldots \ldots \ldots \ldots \ldots \ldots$ & 13 & 1 & 7.5 & 1 & 0 & 0.0 \\
\hline$\ldots \ldots \ldots \ldots \ldots$ & 30 & 1 & 3.4 & 2 & 0 & 0.0 \\
\hline $1910 \ldots \ldots \ldots \ldots \ldots \ldots \ldots \ldots \ldots$ & 70 & 7 & 10.0 & 12 & 0 & 0.0 \\
\hline $1911 \ldots \ldots \ldots \ldots \ldots \ldots \ldots \ldots \ldots$ & 117 & 9 & 7.7 & 14 & 0 & 0.0 \\
\hline $1912 \ldots \ldots \ldots \ldots \ldots \ldots \ldots \ldots \ldots \ldots$ & 80 & 5 & 6.3 & 20 & 0 & 0.0 \\
\hline 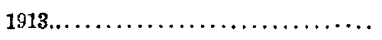 & 114 & 20 & 17.5 & 23 & 1 & 4.3 \\
\hline 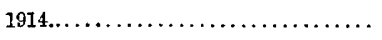 & 71 & 7 & 9.9 & 25 & 3 & 12.0 \\
\hline 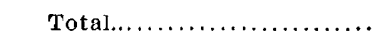 & 523 & 53 & 10.1 & 101 & 4 & 4.0 \\
\hline
\end{tabular}

In Table 2 are summarized the total number of incident cases of pellagra among women in the age period 12 to 49 years at the time of onset of pellagra, together with the total recorded cases of childbirth prior to onset among these women. These are grouped according to race and year of onset. That 10.1 per cent. of the pellagrous white women suffered onset of pellagra following childbirth suggests very strikingly that the puerperal state may predispose to pellagra. ${ }^{4}$

4. Less than 10 per cent. of the women in this population, on the average, will have borne a child within six months. If 10 per cent. of them should have borne a child within six months, at any given time, it would require that the average woman bring forth one child every five years, or a little more than seven children in the thirty-eight years (12 to 49 , inclusive) of her assumed childbearing period. This figure is unquestionably too large for the average woman of this population. 
This hypothesis may be strengthened by a detailed examination of the histories of these mothers. In the citations which follow there have been recorded, so far as the records permit, any complicating disorders which might have influence on the physical condition of the mother prior to onset of pellagra. The cases are grouped for consideration according to the year of onset, with the exception of those incident in a year prior to 1908 . The latter are considered in one group. Of these, twenty-eight were of childbearing age at time of onset and for three of them there is history of childbirth within a period of six months preceding the onset of pellagra.

Pellagrin 354 was 16 years old when she suffered her first attack of pellagra in the summer of 1901, following childbirth. In this case is recorded the complication of puerperal insanity, which appeared just prior to development of pellagra. The initial attack was a severe one, in which skin, gastro-intestinal and mental symptoms were well marked. The patient gave a history of recurrent erythema and mental disturbance nearly every summer to death in February, 1910.

Peliagrin 1024, aged 23 at onset, had her initial attack in the summer of 1905 , following a childbirth. For this case there is a history of freedom from attack for four years subsequent. But in 1910 she again developed frank symptoms and continued to suffer recurrences each summer to 1914 , inclusive.

Pellagrin 543, aged 36 at onset, suffered her first attack of pellagra in the spring of 1905, about two months after childbirth. She suffered annual recurrence to 1913. In 1914 she remained free from recurrence up to the time of her last observation, which was made in July.

Of the thirteen white women of childbearing age with onset of pellagra in 1908, there is one for whom there is recorded a childbirth preceding the onset of pellagra.

Pellagrin 1024, aged 23 at onset, had her initial attack in the summer of 1905 , 1908. In July of the same year symptoms of pellagra first developed and persisted to her death in January, 1909.

In 1909 there were thirty instances of initial attack of pellagra among white women of childbearing age. For one of these there is a history of childbirth prior to onset.

Pellagrin 59, aged 35 at onset, first developed symptoms of pellagra in March, 1909, three months after the birth of her child. At this time she suffered from loss of appetite, insomnia and nervousness. The erythema in this first attack did not appear until June. She suffered a recurrence each summer thereafter to 1914 , during which year she remained free from symptoms.

Of the seventy white women of childbearing age who suffered initial attacks in 1910, there were seven who gave a history of childbirth prior to attack of pellagra.

Pellagrin 702, aged 23 at onset, suffered her first attack in October, 1910. After the birth of twins earlier in the year menstruation had not reappeared. She suffered recurrences in 1911 and 1912. In 1913, after a childbirth in April, she had a recurrence of symptoms in May. In April, 1914, she also suffered recurrence. 
Pellagrin 544, aged 23 at the time of onset, first developed pellagra in the fall of 1910, about one month after the birth of her child. In 1911 she gave birth to a child in the summer and escaped recurrence of symptoms during that year and also during 1912; but a few days after childbirth in April, 1913, she suffered a recurrence. There is no record for 1914.

Pellagrin 112, aged 24 at onset, gave birth to a child in March, 1910. The following June she suffered her first attack of pellagra. In 1911 she had a recurrence, but escaped in 1912. In April, 1913, while she was pregnant, she suffered a recurrence. In 1914 she remained free from symptoms.

Pellagrin 998, aged 27 at the time of onset, had her first attack of pellagra in June, 1910, just one month after the birth of a child. This patient gave a history of indigestion for several months before the birth of her child and of sore mouth, persistent diarrhea and insomnia prior to the development of the erythema. Her ill health continued till death in June, 1911.

Pellagrin 860, aged 32 at onset, first developed an erythema in August, 1910, shortly after giving birth to a child. During 1911, 1912 and 1913 she remained quite free from symptoms of pellagra. In 1914, however, while she was again pregnant, she suffered a recurrence in February, about five weeks before her child was born. The pellagrous symptoms persisted and the patient died in June, 1914.

Pellagrin 292, aged 39 at onset, gave birth to a child in January, 1910. She had a definite attack of pellagra in the following June. She suffered recurrences each year to 1914, during which year she is said to have remained free from symptoms.

Among the 117 white women of childbearing age incident in 1911, there are nine instances of onset following a childbirth.

Pellagrin 269, aged 23 at onset, suffered her initial attack in May, 1911, just. three weeks after the birth of her child. She had recurrences each year thereafter to 1914, inclusive. In 1913, while she was pregnant, pellagrous symptoms developed in May, two months before the birth of her child.

Pellagrin 980, aged 25 at onset, gave birth to a child in June, 1911. At that time she was suffering from severe stomatitis and the erythema appeared soon after. The mental symptoms became marked in this case, and after she had made an attempt to take the life of her child, a nurse was in constant attendance. The pellagrous symptoms recurred in 1912 and persisted until death in August of the same year.

Pellagrin 678, aged 26 at onset, gave birth to a child in March, 1911. In the following summer symptoms of pellagra first developed. In 1912 she was pregnant during the pellagra season, giving birth to a child in October. She remained quite free from symptoms during that year and also during 1913 and 1914.

Pellagrin 122, aged 27 at time of onset, suffered an initial attack of pellagra two or three weeks after the birth of her child in March, 1911. She had no recurrence of symptoms to 1914, inclusive. In 1912 she was pregnant through the greater part of the pellagra season, giving birth to a child in August.

Pellagrin 81, aged 27 at onset, gave birth to a child in May, 1911. She suffered from diarrhea for a month before the baby was born, and the erythema appeared in June. In 1912 she had a recurrence of erythema. She remained quite free from symptoms during 1913 and 1914.

Pellagrin 883, aged 30 at the time of onset, first developed an erythema five weeks after the birth of her child in March, 1911. She remained free from symptoms during 1912, but suffered a recurrence in 1913. In 1914 she escaped recurrence.

Pellagrin 281, aged 32 at onsct, gave birth to a child in February, 1911. Her baby had persistent bowel trouble and died at the age of 4 months. In July, 1911, shortly after the death of the child, the mother had her initial attack of pellagra. She remained free from symptoms of the disease in 1912, during which 
year she was pregnant until November. She also escaped recurrence in 1913, but suffered an attack in 1914.

Pellagrin 1137, aged 34 at onset of pellagra in the spring of 1911, gives a history of the appearance of pellagrous symptoms following the birth of her two children in 1911 and 1913, respectively. In 1912 and 1914 she remained free from the disease.

Pellagrin 238, aged 38 at onset, gave birth to a child in February, 1911, and suffered her first attack of pellagra in the following May or June. After that she remained entirely free from symptoms up to the last observation in June, 1914.

Of the eighty white women of childbearing age with onset in 1912 , there are five with definite record of childbirth just prior to the initial attack of pellagra.

Pellagrin 596, aged 19 at onset, gave birth to a child in December, 1911. The following spring (1912) she had her initial attack of pellagra. In July, 1913, she had a recurrence. She was pregnant in 1914 from February and remained free from symptoms during that year.

Pellagrin 614, aged 27 at time of onset, suffered her initial attack of pellagra shortly after giving birth to a child in August, 1912. In 1913 and 1914 she suffered complete, though mild, recurrences in May and March, respectively. In 1914 she was pregnant until July.

Pellagrin 1000, aged 29 at onset, was in poor health after the birth of her last child in January, 1912. The following March (1912) the erythema appeared for the first time. In March, 1913, she suffered a recurrence of symptoms and she died in April, 1913.

Pellagrin 164, aged 30 at the time of onset, suffered an initial attack of pellagra in June, 1912, two months after the birth of a child. In 1913 she was pregnant from June. She remained free from symptoms during 1913. In February, 1914, she gave birth to a child, but up to June of that year had suffered no recurrence.

Pellagrin 1185, aged 35 at onset, gave birth to a child in January, 1912. She had her initial attack in the following April (1912). In 1913 she remained free from symptoms, but suffered a recurrence in 1914.

In 1913 there were 114 white women of childbearing age who had an initial attack of pellagra. For twenty-one of these there is a record of a childbirth prior to onset.

Pellagrin 798, aged 18 at time of incidence in June, 1913, had given birth to a child three months before. She died of pellagra in July, 1913.

Pellagrin 635, aged 20 at onset, had given birth to a child late in December, 1912. Peliagra developed the following April (1913). During 1914 she remained free from symptoms.

Pellagrin 872 , aged 22 at the time of onset, gave birth to a child in May, 1913. The following June she developed an initial erythema. In 1914 she remained free from symptoms.

Pellagrin 549 was 23 years old when she had her first attack of pellagra in June, 1913. She had given birth to a child the preceding March. She remained free from recurrence the following year.

Pellagrin 1034, aged 23 at onset, suffered a first attack of pellagra in August, 1913, just one month after giving birth to a child. She had a recurrence in July, 1914.

Pellagrin 837 , aged 23 at the time of onset, gave birth to a child in March, 1913. She developed pellagrous symptoms for the first time in August, 1913. In 1914 she escaped recurrence. 
Pellagrin 741, aged 24 at onset, suffered her initial attack of pellagra in June, 1913, two months after a childbirth. She had a severe recurrence in May, 1914. Pellagrin 639, aged 24 at onset, gave birth to a child in February, 1913. The following May (1913) she had her first attack of pellagra. In 1914 she was reported to have had a severe recurrence during the spring and summer.

Pellagrin 552, aged 24 at onset, gave birth to a child in January, 1913. The following May (1913) she developed pellagra for the first time. In 1914 she remained free from symptoms.

Pellagrin 559, aged 24 at onset, gave birth to a child in February, 1913. She suffered her initial attack the following May. In 1914 she escaped recurrence.

Pellagrin 904, aged 25 at onset, gave birth to a child in September, 1913. Her health was very poor after childbirth, and in December, 1913, she developed symptoms of pellagra. She suffered a recurrence of the disease in 1914.

Pellagrin 576, aged 25 at onset, gave birth to a child in December, 1912. She had poor health during the months following, and in June, 1913, suffered her first attack of pellagra. In 1914 she had a slight recurrence of symptoms.

Pellagrin 591, aged 26 at onset, was nursing her 5-months-old baby when pellagra first developed in June, 1913. She is without record for 1914.

Pellagrin 458, aged 26 at onset, gave birth to a child in January, 1913. She began to feel ill in March, but continued to nurse her baby until pellagra developed in May, 1913. She remained free from symptoms during 1914.

Pellagrin 498, aged 28 at onset, suffered her first attack in June, 1913, about three months after the birth of her child. During 1914 she was pregnant until September. She remained free from symptoms of pellagra in 1914.

Pellagrin 700, aged 29 at onset, gave birth to a child in May, 1913, and pellagra developed at about the same time. She grew progressively worse and was admitted to the hospital on August 10, where she died two weeks later.

Pellagrin 1031, aged 29 at onset, had suffered from stomatitis in the fall of 1912. She gave birth to a child in January, 1913, and diarrhea developed shortly afterward, followed by a severe erythema in July. These symptoms persisted until death in October, 1913.

Pellagrin 537, aged 29 at onset, was in poor health before and following the birth of her child in October, 1912. In March, 1913, she developed an erythema for the first time. During 1914 she was pregnant until September, and remained free from symptoms during that year.

Pellagrin 665, aged 30 at onset, had an initial attack in May, 1913. Following the birth of her child three months before, she had been in poor health. During 1914 she remained free from symptoms.

Pellagrin 610, aged 32 at the time of onset, gave birth to a child in December, 1912. In the following June (1913) she suffered her initial attack of pellagra. In 1914 she escaped recurrence of symptoms.

Pellagrin 294, aged 36 at onset, gave birth to a child in February, 1913, and had her first attack of pellagra in April. She grew worse and was admitted to the Good Samaritan Hospital in July. Against the advice of her physician she left the hospital in August and died in October, 1913.

In 1914 there were seventy-one incident cases of pellagra recorded among white women of childbearing age. For seven of the white women, or 9.9 per cent., there is record of a possibly predisposing childbirth.

Pellagrin 1250, aged 20, had a severe attack of dysentery in May, 1914, about two weeks after the birth of her child. The pellagrous erythema did not appear until the second week in October.

Pellagrin 922, aged 22 at onset, gave birth to a child the last of February, 1914. She developed initial symptoms of pellagra the last of April. 
Pellagrin 1155, aged 22 at time of onset, gave birth to a child in the latter part of January, 1914. She first developed erythema in the following July.

Pellagrin 954, aged 26 at onset, suffered an initial attack in June, 1914, about six weeks after a childbirth.

Pellagrin 1019, aged 27, gave birth to a child early in May, 1914, and first developed pellagrous symptoms about two weeks after delivery.

Pellagrin 1011, aged 29 at onset, gave birth to a child the last of May, 1914, and two months later suffered an initial attack of pellagra. In the case of this patient there was a complication of diarrhea which had persisted from the fall of 1913.

Pellagrin 1161, aged 33 at time of onset, gave birth to a child in March, 1914, and developed initial pellagrous symptoms about four weeks after delivery.

TABle 3.-Pellagrins Who Suffered the Initial Atrack Within One Month After Childbirth

\begin{tabular}{|c|c|c|c|c|}
\hline $\begin{array}{l}\text { Pellagrin } \\
\text { Number }\end{array}$ & $\begin{array}{c}\text { Age at } \\
\text { Onset }\end{array}$ & $\begin{array}{l}\text { Date of } \\
\text { Childbirth }\end{array}$ & $\begin{array}{l}\text { Onset of } \\
\text { Pellagra }\end{array}$ & $\begin{array}{l}\text { Interval Indieated by } \\
\text { the Original Record }\end{array}$ \\
\hline $\begin{array}{r}\text { White Women- } \\
\quad 354 . . \ldots \ldots \ldots . . .\end{array}$ & 16 & Summer, 1901 & Summer, 1901 & Following childbirth \\
\hline 1024. & 23 & Summer, 1905 & Summer, 1905 & Following childbirth \\
\hline $1107 \ldots$ & 18 & Summer, 1908 & July, 1908 & Following soon after \\
\hline 544. & 23 & Fall, 1910 & Fall, 1910 & About one month after \\
\hline 998. & 27 & May, 1910 & June, 1910 & One month \\
\hline 860. & 32 & August, 1910 & August, 1910 & Following childbirth \\
\hline 269. & 23 & May, 1911 & May, 1911 & Three weeks after child- \\
\hline $980 \ldots$ & 25 & June 5, 1911 & June, 1911 & Soon after childbirth \\
\hline 122. & 27 & March, 1911 & Late March, 1911 & Two or three weeks \\
\hline 81. & 27 & May 8, 1911 & June, 1911 & About one month \\
\hline 1137. & 34 & Spring, 1911 & Spring, 1911 & Foliowing childbirth \\
\hline $614 .$. & 27 & August, 1912 & September, 1912 & Following childbirth \\
\hline 1034 & 23 & July 1, 1913 & August, 1913 & One month \\
\hline 700 & 29 & May, 1913 & May, 1913 & At about same time \\
\hline 1019. & 27 & May, 1914 & May, 1914 & About two weeks \\
\hline 1161. & 33 & March, 1914 & April, 1914 & Four weeks \\
\hline
\end{tabular}

Of the 101 colored women incident before 1915, there is a history of a previous childbirth for four.

Pellagrin 410, aged 25 at onset, first developed symptoms of pellagra in the spring of 1913, following a childbirth, the exact date of which is not recorded. She died of pellagra in July, 1913.

Pellagrin 943, aged 21, gave birth to a child in January, 1914. During the early months of her pregnancy she had lived with her grandmother, Pellagrin 539, who died of pellagra during the summer of 1913. The patient remained free from symptoms during that year. In May, 1914, however, four months after the birth of her child, she developed pellagra for the first time.

Pellagrin 1094, aged 21 at onset, gave birth to a child early in June, 1914. In August she suffered an initial attack of pellagra.

Pellagrin 923, aged 24 at the time of onset, developed pellagra for the first time in May, 1914, about four or five months subsequent to a childbirth. The symptoms persisted until death, June 24, 1914. 
Of the ninety-six women aged 12 to 49 years with initial attack of pellagra in 1914, there are, therefore, ten instances of a possibly predisposing childbirth, or 10.4 per celit., for both races. If these incident cases with their proportion of prior childbirths are added to those of women incident before 1914 with their respective cases of childbirth, we have a total of fifty-seven possibly predisposing childbirths among 624 pellagrous women, or a percentage of 9.1 for both races. This

TABle 4.-Pellagrins Who Suffered the Initial Attack Later Than One Month But Within Three Months After Childbirth

\begin{tabular}{|c|c|c|c|c|}
\hline $\begin{array}{l}\text { Pellagrin } \\
\text { Number }\end{array}$ & $\begin{array}{l}\text { Age at } \\
\text { Ouset }\end{array}$ & $\begin{array}{l}\text { Date of } \\
\text { Childbirth }\end{array}$ & $\begin{array}{l}\text { Onset of } \\
\text { Pellagra }\end{array}$ & $\begin{array}{l}\text { Interval Indicated by } \\
\text { the Original Record }\end{array}$ \\
\hline $\begin{array}{r}\text { White Women- } \\
543 . . . . \ldots \ldots \ldots\end{array}$ & 36 & Early in 1906 & Spring, 1906 & About two months \\
\hline 702. & 23 & Late summer & October, 1910 & About three months \\
\hline 112. & 24 & March 19,1910 & June, 1910 & Three months \\
\hline $883 \ldots$ & 30 & March 21, 1911 & April, 1911 & Five weeks \\
\hline $1000 .$. & 29 & January, 1912 & March, 1912 & Two months \\
\hline $164 .$. & 30 & April, 1912 & June, 1912 & Two months \\
\hline $1185 \ldots$ & 35 & January, 1912 & April, 1912 & Three months \\
\hline $798 .$. & 18 & March, 1913 & June, 1913 & Three months \\
\hline $872 \ldots \ldots$ & 22 & May 10,1913 & July, 1913 & Two months \\
\hline $549 \ldots \ldots \ldots \ldots \ldots$ & 23 & March, 1913 & June, 1913 & Three months \\
\hline $741 \ldots .$. & 24 & April, 1913 & June, 1913 & Two months \\
\hline $639 \ldots$ & 24 & February, 1913 & May, 1913 & Three months \\
\hline $559 \ldots \ldots \ldots \ldots$ & 24 & February, 1913 & May, 1913 & Three months \\
\hline $904 \ldots \ldots \ldots \ldots$ & 25 & September, 1913 & December, 1913 & Three months \\
\hline $498 \ldots \ldots \ldots$ & 28 & March, 1913 & June, 1913 & Three months \\
\hline $665 \ldots$ & 30 & February, 1913 & May, 1913 & Three months \\
\hline $294 \ldots \ldots \ldots \ldots \ldots \ldots$ & 36 & February, 1913 & April, 1913 & Two months \\
\hline $822 \ldots \ldots \ldots \ldots \ldots \ldots$ & 22 & February, 1914 & April, 1914 & Two months \\
\hline $954 \ldots \ldots \ldots \ldots \ldots \ldots$ & 26 & May, 1914 & June, 1914 & Six weeks \\
\hline $1011 \ldots \ldots \ldots \ldots$ & 29 & May, 1914 & July, 1914 & Two months \\
\hline $\begin{array}{l}\text { Colored Women } \\
\quad 410 \ldots \ldots \ldots \ldots \ldots \ldots\end{array}$ & 25 & Early in 1913 & Spring, 1913 & Not recorded \\
\hline 1094. & 21 & June, 1914 & August, 1914 & Two months \\
\hline
\end{tabular}

indicated percentage is undoubtedly too small, for the records of very many of these 624 women are incomplete, especially in respect to dates of childbirths. Indeed it was not until the year 1913 that the subject of the possible predisposition of puerperal women to pellagra was given any particular attention. Thus, we find the tabulations for that year and for 1914 more complete and, therefore, more reliable criteria in regard to this relationship than are the recorded data for the pre- 
ceding years. In this connection it should be mentioned that the records for the latter part of 1914 are incomplete because of the termination of the field work of the commission in the fall of that year.

The fifty-seven examples of onset of pellagra within six months after childbirth are presented in Tables 3, 4 and 5, separately, according to the length of the interval between childbirth and the onset of the initial attack. Those with onset of pellagra in the first month

TABlE 5.-Pellagrins Who Suffered the Initial Attack Later Than Three Months But Within Six Months After Childbirth

\begin{tabular}{|c|c|c|c|c|}
\hline $\begin{array}{l}\text { Pellagrin } \\
\text { Number }\end{array}$ & $\begin{array}{c}\text { Age at } \\
\text { Onset }\end{array}$ & $\begin{array}{l}\text { Date of } \\
\text { Childbirth }\end{array}$ & $\begin{array}{l}\text { Onset of } \\
\text { Pellagra }\end{array}$ & $\begin{array}{l}\text { Interval Indicated by } \\
\text { the Original Record }\end{array}$ \\
\hline $\begin{array}{r}\text { White Women- } \\
59 \ldots \ldots \ldots \ldots\end{array}$ & 35 & December, 1908 & June, 1909 & Six months \\
\hline $292 \ldots$ & 39 & January, 1910 & June, 1910 & Five months \\
\hline $678 .$. & 26 & March, 1911 & Summer, 1911 & Not recorded \\
\hline $281 \ldots$ & 32 & February, 1911 & July, 1911 & Five months \\
\hline $238 \ldots$ & 38 & February, 1911 & May or June, & Three or four months \\
\hline $596 \ldots$ & 19 & December, 1911 & Spring, 1912 & Not recorded \\
\hline $635 .$. & 20 & Dec. 22, 1912 & April, 1913 & Four months \\
\hline $837 \ldots$ & 23 & March, 1913 & August, 1913 & Five months \\
\hline $552 \ldots$ & 24 & January, 1913 & May, 1913 & Four monthe \\
\hline $576 .$. & 25 & December, 1912 & June, 1913 & Six months \\
\hline $591 .$. & 26 & January, 1913 & June, 1913 & Five months \\
\hline $458 \ldots$ & 26 & Jan. 10, 1913 & May, 1913 & Four months \\
\hline $1031 .$. & 29 & January, 1913 & Juiy, 1913 & Six months \\
\hline $537 .$. & 29 & October, 1912 & March, 1913 & Five months \\
\hline $610 . .$. & 32 & December, 1912 & June, 1913 & Six months \\
\hline $1250 \ldots$ & 20 & May, 1914 & October, 1914 & Five months \\
\hline $1155 \ldots$ & 22 & January, 1914 & July, 1914 & Six months \\
\hline $\begin{array}{r}\text { Colored Women- } \\
943 . \ldots \ldots \ldots \ldots\end{array}$ & 21 & January, 1914 & May, 1914 & Four months \\
\hline 923. & 24 & $\begin{array}{l}\text { January or Feb- } \\
\text { ruary, } 1914\end{array}$ & May, 1914 & Three or four months \\
\hline
\end{tabular}

after delivery are shown in Table 3 . These number sixteen, all white women, and constitute 32.2 per cent. of the white women in the whole group. In Table 4 are shown the twenty-two pellagrins who suffered initial attack in the second and third months following childbirth. Twenty of these were white women, making up 37.7 per cent. of the fifty-three white women in the whole group. In Table 5 are shown nineteen pellagrins who developed the disease in the fourth, fifth or sixth month following childbirth, seventeen of these being white women. This group is approximately equal to that shown in Table 3, 
indicating that onset of pellagra has been about three times as common in the first month following pregnancy as in either the fourth, fifth or sixth month following such an event. Furthermore, this group shown in Table 5 is one half as large as the sum of those in Tables 3 and 4, indicating that onset of pellagra has been about twice as frequent in the first three months following childbirth as it has been in the succeeding three months. These relationships certainly suggest that the event of childbirth may be an important factor in predisposing to pellagra and that it may also determine to some degree the onset of definite symptoms of the disease.

Another interesting relation shown by these tables is that of season. Of the sixteen childbirths recorded in Table 3 , no less than fifteen occurred in the spring or summer months. On the other hand, of the nineteen childbirths shown in Table 5, only two occurred during spring

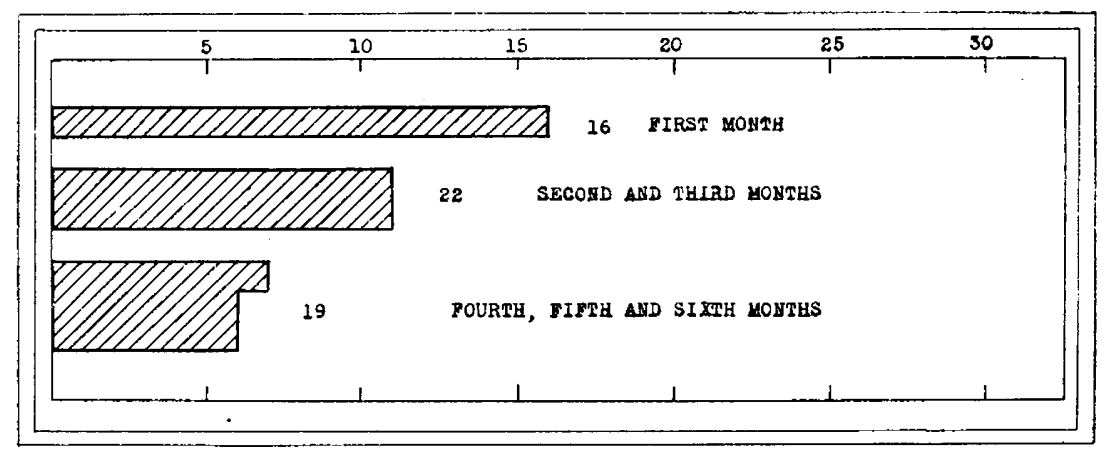

Fig. 2.-The number of initial attacks of pellagra following childbirth. Note that there were sixteen in the first month, twenty-two in the second and third months and nineteen in the fourth, fifth and sixth months after delivery.

or summer and no less than fourteen of them took place in the three winter months, December, January and February. It is evident that the danger of pellagra developing within a few weeks after childbirth is greatest when the pregnancy terminates during the spring or summer and, from what has been said above, it would seem that the cases of this kind are the ones to which childbirth has the most definite relation.

THE RELATION OF RECURRENT ATTACK OF PELLAGRA TO PREGNANCY

\section{AND CHILDBIRTH}

In the preceding discussion the relation of the first or initial attack of pellagra to certain physiologic conditions of the woman have been considered. In this section we purpose to consider the subsequent behavior of all women who survived the year of initial attack and who presented a definite record of subsequent pregnancy or childbirth, 
in order to ascertain whether there is any correlation, either positive or negative, between the pregnant state and recurrence of pellagra or between the puerperal state and recurrence of pellagra. In the preceding paper $^{5}$ of this series has been presented the correlation between recurrence of pellagra, on the one hand, and race, sex and age, on the other, and it was there suggested that pregnancy and childbirth seemed to influence the behavior of the women in respect to recurrence. In that paper all the women who suffered the initial attack of pellagra previous to the year 1914 were considered. Here, those of this same group for whom there is a definite record of pregnancy or of childbirth after the onset of pellagra will be considered.

There are, in all, eighty-three white women and four colored women in this category, including fifteen ${ }^{6}$ of the twenty women who suffered the initial attack of pellagra during pregnancy. For a considerable part of these, however, there is a definite record of more than one pregnancy per patient, so that the number of instances of pregnancy or of childbirth in surviving pellagrins available for the present discussion is 101 in white women and five in colored women.

Among the white pellagrins with onset previous to 1908 there is only one with a definitely recorded history of pregnancy or childbirth subsequent to onset of pellagra.

Peilagrin 70, aged 27, suffered her initial attack in 1905 . Every spring thereafter she had bowel trouble, sore mouth and nervous disturbance, but the evidence of definite recurrent erythema is lacking until 1913. She was pregnant in 1907 or 1908 and miscarried, but the record of this pregnancy is not definite enough to be of value here. In 1913 she gave birth to a child in April, suffered a definite recurrence of pellagra in August and died in January, 1914, of pellagra and complicating disorders.

Of the white pellagrins who survived the initial attack in 1908 there are five with definite record of pregnancy or of childbirth after the onset of pellagra.

For the history of Pellagrin 186 see the section on Initial Attack During Pregnancy.

Pellagrin 432, aged 24, suffered her first attack of pellagra in 1908, with severe recurrence in 1909, but no recurrence in 1910 . She became pregnant in August, 1910, giving birth to her child in May, 1911. The years 1911 and 1912 were passed without reappearance of pellagra. She again conceived in August, 1912, and was delivered in May, 1913. This time an attack of pellagra

5. Siler, J. F., Garrison, P. E., and MacNeal, W. J.: The Relation of Recurrent Attacks of Pellagra to Race, Sex and Age of the Patient and to Treatment of the Disease, The Archives Int. Med., 1916, 18, 652.

6. For three cases with onset of pellagra in 1914 during pregnancy, namely, Pellagrins 977, 958 and 1078, data subsequent to delivery are not available. For two cases, Pellagrins 827 and 260 , with initial attack during pregnancy, pellagrous symptoms persisted after delivery. These five cases are excluded from this category. 
appeared during the puerperium and there was another definite recurrence in 1914.

For history of Pellagrin 277 see the section on Initial Attack During Pregnancy.

Pellagrin 987 was 25 years old in the summer of 1908, when her pellagrous symptoms first appeared. In September, 1908, she became pregnant. She suffered a mild recurrence of pellagra the following spring before childbirth, which occurred June 10, 1909. Every spring thereafter to 1914, inclusive, she had recurrences, mild symptoms developing in 1912 during a pregnancy, which was terminated by childbirth in November, 1912.

Pellagrin 37, aged 32 at the time of onset, suffered her first attack in the fall of 1908. Each spring thereafter she had a recurrence, although in 1911, after an early recurrence, she remained entirely free from symptoms after April, when she became pregnant, being delivered the following December. In April, 1912, while still nursing her baby, she suffered another recurrence, and pellagra again recurred the following spring (1913). In August, 1913, she again became pregnant and remained free from symptoms of pellagra in 1914 until after childbirth on May 15. At our last observation in June, 1914, slight but definite signs of a recurrence of pellagra were already present.

Of the seven instances of pregnancy subsequent to onset of pellagra there are, therefore, five in which the pregnancy terminated in the early summer and two in which childbirth occurred in the late fall. Of the five pregnancies terminating in the summer, four were free from recurrence of pellagrous symptoms, while in one instance a mild attack of pellagra developed in the sixth or seventh month. In the two instances of childbirth in the fall the patient remained quite free from the disease during pregnancy in one and in the other a mild recurrence appeared in the first or second month of pregnancy.

There were two instances of a childbirth following onset during pregnancy. In one of these cases the childbirth occurred in July, in the other it occurred in the fall. There were, therefore, nine instances Jf childbirth subsequent to onset of pellagra, six occurring in the summer and three in the fall. In seven of these the mother remained entirely free from symptoms for a period of at least three months rollowing her delivery, and in two there was recurrence in the summer within four weeks after the childbirth.

Of the white pellagrins with initial attack in 1909, there are nine for whom definite records of pregnancy, or of childbirth subsequent to onset, are available.

Pellagrin 817, aged 17 at onset in 1909, became pregnant soon after and remained entirely free from any symptoms of pellagra up to our last observation in 1914 .

Pellagrin 94 suffered her first attack in April, 1909, when 21 years of age. The following year she had a recurrence in April. In 1911 she suffered a very severe recurrence, being confined to bed for three months. In July, 1911, she became pregnant, giving birth to a child in March, 1912. In this case a pregnancy during the cool season was succeeded by a very mild recurrence in June, 1912. Late in the summer of 1912 she became pregnant and aborted in October, 1912. In February, 1913, she became pregnant again and 
remained entirely free from symptoms for that year. In 1914 she again suffered a recurrence of pellagra.

Pellagrin 178 was 23 years old at the time of her initial attack in the spring of 1909. She recovered and remained free from symptoms until 1912. After childbirth early in 1912 she suffered a recurrence of pellagra in March and in 1913 she had another mild recurrence. In January, 1914, she became pregnant and escaped recurrence of pellagra to the date of the last observation, July 7, 1914.

Pellagrin 151 suffered her first attack in March, 1909, when 23 years of age. Each subsequent spring she had a recurrence up to and including 1912. In July, 1912, she became pregnant. Her baby was born in March, 1913. She remained entirely free from symptoms of pellagra during 1913 and 1914.

Pellagrin 119, aged 25, had her initial attack in July, 1909. The following March she became pregnant and remained free from symptoms of pellagra during 1910. In 1911 she had no recurrence and again became pregnant in August. After a winter pregnancy, terminated by childbirth April 29, 1912, she remained quite free from symptoms during 1912, but in 1913 she suffered a recurrence. She is without record in 1914.

Pellagrin 140, aged 25, suffered her first attack in May, 1509. She had a recurrence in 1910, and in 1911 the symptoms reappeared in April. In June, 1911, she became pregnant. After giving birth to a child in February, 1912, she had a very severe recurrence in June, 1912, and died of pellagra on Aug. 17, 1912.

Pellagrin 80 was 26 years old when she suffered her initial attack early in the summer of 1909. In 1910 she had no recurrence of pellagra, but in July, 1911, while she was pregnant, she had a very severe recurrence and after delivery in August, 1912, her hands broke out a second time. Thereafter, from 1912 to 1914, inclusive, she was entirely free from symptoms of the disease.

For history of Pellagrin 644 see section on Initial Attack During Pregnancy.

Pellagrin 1346, aged 30 at the time of onset of pellagra in 1909, suffered recurrences in 1910 and 1911. In 1912 she was pregnant until September and during that year remained free from symptoms. In 1913 she also escaped recurrence of the erythema, although she had sore mouth and some physical weakness. She is without record for 1914.

Among the white pellagrins with initial attack in 1909 there were, therefore, thirteen instances of pregnancy subsequent to onset of pellagra. In five cases childbirth occurred in the early months of the year (from January to April, inclusive), in one case it occurred in late summer and in six instances the period of pregnancy extended over the entire pellagra season, with termination in the fall. In one instance the exact season of gestation was not recorded. With one exception the patients were entirely free from symptoms of pellagra during all these pregnancies. In the case of the pregnancy with summer termination, however, a severe recurrence was suffered in the eighth month and after childbirth in August a second erythema developed within four weeks.

There was one case of initial attack during pregnancy with subsequent childbirth, making a total of fourteen instances in this category in 1909. For one 1914 pregnancy records of subsequent history are not available. For ten of the thirteen remaining cases there was no recurrence of pellagra for three months subsequent to delivery; two 
of the instances of childbirth early in the year were followed by recurrence within three months and the one instance of childbirth late in the summer was followed by a recurrence of pellagra within one month.

Among the white pellagrins with initial attack in 1910 there are seventeen with a definite history of pregnancy or of childbirth subsequent to onset.

Pellagrin 824, aged 17 at onset of pellagra in 1910, suffered a mild recurrence in 1911, apparently during a pregnancy which began in April. Her child was born in December. In 1912, 1913 and 1914 she remained free from recurrence of pellagra.

Pellagrin 750 was 18 years of age when she had her initial attack in 1910. For 1911 and 1912 there are no definite records of recurrence. In July, 1912, she became pregnant and gave birth to a child in March, 1913. The following August she suffered a mild recurrence and again had a renewal of symptoms in 1914 .

Pellagrin 275 had her first attack of pellagra in the spring of 1910, when she was 18 years old. She has had a recurrence each year thereafter up to and including 1914. In 1913 she became pregnant in March, suffered a mild recurrence of pellagra in June and was delivered the following December. This is an instance of recurrence of pellagra coincident with pregnancy during the summer season.

Pellagrin 1153, aged 19 at the time of onset of pellagra in the summer of 1910, remained entirely free from symptoms of pellagra during the four years subsequent. In 1913 a childbirth was recorded, but the season of pregnancy was not noted.

Pellagrin 702, aged 23, suffered her first attack in October, 1910. She had recurrences each year thereafter. She gave birth to a child in April, 1913, and suffered a recurrence of pellagra in May, 1913.

Pellagrin 544, aged 23, suffered her first attack in the fall of 1910, about one month after childbirth. In 1911 she was free from symptoms. She also gave birth to a child in the summer of that year, but the exact month of delivery is not recorded. In 1912 she was also free from recurrence of pellagra, but in 1913 after giving birth to a child in April she promptly developed pellagrous symptoms. For 1914 the record is uncertain.

Pellagrin 112, aged 24, first developed symptoms of pellagra in June, 1910, a few weeks after childbirth. In 1911 she suffered a recurrence and also had an induced abortion at six months in December. She remained free from symptoms during 1912, again becoming pregnant in December, 1912. In April, 1913, she suffered a mild recurrence while still pregnant. The child was born in August of the same year. In 1914 the patient remained free from symptoms.

Pellagrin 218, aged 25, had her initial attack in the summer of 1910, the exact month of onset being unrecorded. In June, 1910, she became pregnant, giving birth to a child in February, 1911. Early in 1911 she had a recurrence of pellagra, but the exact date is not recorded. In April of the same year she again became pregnant and the child was born in January, 1912. The following March she suffered her second recurrence. In May, 1913, pellagrous symptoms again developed. In July, 1913, she became pregnant a third time, and five weeks after delivery, on March 28, 1914, she suffered her fourth recurrence of pellagra. Here, then, are three instances of recurrence following within three months after childbirth.

Pellagrin 282, aged 26, had her initial attack in September, 1910. She had a recurrence in September, 1911, but in 1912 she remained free from symptoms. 
In 1913, after a childbirth in July, she had a recurrence of pellagra with two eruptions of the erythema, and she also had a renewal of symptoms in 1914 .

For history of Pellagrin 95 see section on Initial Attack During Pregnancy.

Pellagrin 127, aged 28 at onset of pellagra in 1910, suffered a recurrence the following year, but remained free from symptoms in 1912. In 1913 she became pregnant in May and escaped recurrence that year. In 1914, after a childbirth in February, she suffered a recurrence of symptoms in the early summer.

Pellagrin 171 was 28 years old when she had her initial attack of pellagra in October, 1910. She had a recurrence in April, 1911, but in 1912 she was pregnant from January and the symptoms of pellagra did not appear. She was again pregnant from January, 1913, and remained free from the disease during that year. In 1914, however, she had a mild recurrence.

Pellagrin 279 was 29 years of age at onset of pellagra in July, 1910. She had a recurrence in 1911, but remained free from symptoms during 1912 and 1913. In February, 1914, she became pregnant and escaped recurrence in that year to the date of the last observation, July 20, 1914.

For history of Pellagrin 18 see section on Initial Attack During Pregnancy.

Pellagrin 860, aged 32, developed her first erythema in August, 1910, shortly after childbirth. During the three following years she remained free from symptoms. In February, 1914, she suffered a severe recurrence about five weeks before the birth of her child and she died of pellagra two months after delivery.

Pellagrin 6, aged 32, had her initial attack in April, 1910. The following October she became pregnant and remained free from symptoms in 1911, being delivered in June. In 1912 she had a recurrence and died Aug. 21, 1912.

Pellagrin 29, aged 40 at the time of onset in 1910, suffered a recurrence in 1911 and 1912. In 1913 she remained free from symptoms and became pregnant in the fall of the same year. She gave birth to a child in May, 1914, and escaped recurrence during that year also.

There are, therefore, among the white pellagrins incident in 1910 nineteen instances of pregnancy subsequent to onset of pellagra. Seven of these terminated early in the year, five in the summer, six in the rall months and for one the exact season was not recorded. Of the pregnancies with termination in the spring, five were quite free from manifestations of pellagra, a severe recurrence in the eighth month was suffered in one and for the seventh there was no definite history. Of the five pregnancies with childbirth in the summer, four were free from symptoms and a mild recurrence in the fifth month of gestation occurred in the fifth case. Of the six instances of pregnancy with fall termination, three were entirely free from symptoms, mild recurrences in the early months were suffered in two and for the sixth there was no definite history.

Among the white pellagrins incident in 1910 there were two cases of onset during pregnancy and one case in which the onset month was uncertain, with subsequent childbirth. For these three cases of childbirth subsequent to onset, as well as for eighteen of the nineteen instances of pregnancy just mentioned above, the pellagrous history of the mother following delivery may be considered. For one 1914 pregnancy subsequent history is not available, because our field observations ceased in the fall of that year. Of the twenty-one instances 
of childbirth subsequent to initial attack of pellagra in 1910, therefore, eight occurred in the spring, five in the summer, seven in the fall and for one the exact season was not recorded. In six instances of delivery in the spring a recurrence of pellagra appeared within three months after childbirth, in one case the mother remained free from symptoms and in one instance a severe recurrence during late pregnancy persisted till death two months after delivery. Of the five instances of childbirth in the summer, all but one were free from recurrence of symptoms during the following three months. Of the seven instances of childbirth in the fall and winter, none was followed by recurrence of pellagra within three months.

There are twenty-two white pellagrins with initial attack in 1911 who have a record of pregnancy or of childbirth subsequent to onset of pellagra.

Pellagrin 896 was 19 years old when she had her first attack in April, 1911. In the following September she became pregnant and gave birth to a daughter in May, 1912. Near the termination of this pregnancy, in April, 1912, she suffered a mild recurrence of pellagra. She had recurrence also in 1913 and 1914.

For history of Pellagrin 62 see section on Initial Attack During Pregnancy.

Pellagrin 269, aged 23, suffered her first attack of pellagra in May, 1911, just three weeks after the birth of her child. She had a recurrence in May, 1912. That same year she became pregnant in November and the following spring she suffered a mild recurrence before her child was born. She also had a recurrence in 1914.

For history of Pellagrin 568 see section on Initial Attack During Pregnancy.

For history of Pellagrin 724 see section on Initial Attack During Pregnancy.

Pellagrin 726 was 25 years old when she suffered her first attack of pellagra in May, 1911. In January, 1912, she became pregnant and she remained free from pellagrous symptoms during that year. She also escaped recurrence in 1913, but in June, 1914, while she was again pregnant, she suffered a mild recurrence of symptoms three weeks before the birth of her child.

Pellagrin 678, aged 26 at onset, suffered her initial attack in the summer of 1911, following a childbirth in March. In February, 1912, she again became pregnant, giving birth to a son in October. She remained free from symptoms of pellagra during that entire year and she remained free from recurrence of the disease up to the last observation in May, 1914.

Pellagrin 1033, aged 27 at onset, had her initial attack in the spring of 1911. The year following she suffered a recurrence in March. In September, 1912, she became pregnant and the following spring mild pellagrous symptoms again appeared before the birth of her child in May, 1913. She also had a recurrence in 1914.

Pellagrin 122, aged 27, suffered her initial attack the latter part of March, 1911 , in which month she had given birth to a child. In December, 1911, she again became pregnant and escaped recurrence of the disease during 1912 . She also remained free from symptoms during 1913 and 1914.

Pellagrin 21 was 27 years of age when she suffered her first attack in May, 1911. The following July she became pregnant and after a childbirth in March, 1912, she had a recurrence of pellagra in May. In 1913 she also had a recurrence in March, which subsided by July. This patient died March 4, 1914, without recurrence.

Pellagrin 879 had her initial attack in April, 1911, when she was 29 years of age. In March, 1912, she gave birth to a daughter. She escaped recurrence 
during 1912. She also remained free from symptoms of pellagra in 1913, in which year she again became pregnant in April. She suffered a recurrence of pellagra in April, 1914.

Pellagrin 281. was 32 years of age at the time of onset of pellagra in July, 1911. In February, 1912, she became pregnant and escaped recurrence for that year. She also remained free from symptoms in 1913, but suffered a recurrence in 1914.

Pellagrin 84, aged 32 at the time of her initial attack in 1911, became pregnant in October of that same year. She suffered a recurrence in July, 1912, only a few weeks after the birth of her child. In 1913 and 1914 she was free from symptoms.

Pellagrin 822 was 33 years of age when she suffered her first attack in 1911. She escaped recurrence in 1912, in which year she became pregnant in July. After a childbirth in March, 1913, she also escaped recurrence for that year. In June, 1914, the pellagrous symptoms again appeared.

Pellagrin 274 suffered her first attack in June, 1911, when she was 33 years of age. She became pregnant early in 1912 and remained quite free from symptoms during that year. In 1913 she also escaped recurrence, but in 1914 she had a recurrence of pellagra and she died with complications in September, 1914.

Pellagrin 1137 was 34 years of age when she had her initial attack in the spring of 1911. This patient gives a history of the appearance of pellagrous symptoms after childbirth in 1911 and 1913. The years during which she did not bear children, namely, 1912 and 1914, she remained free from recurrence of the pellagrous symptoms.

Pellagrin 1038, aged 34 at onset of the disease in the summer of 1911, remained free from recurrence during the two years following, although her general health was poor in 1912. In 1913 she gave birth to a child in September, and she was not well thereafter. She suffered a recurrence of pellagra in July, 1914.

Pellagrin 599 had her initial attack in 1911, when 36 years of age. She remained free from symptoms the following year, but suffered a recurrence in July, 1913. In January 1914, she became pregnant and remained free from symptoms during that year up to our last observation in June.

Pellagrin 565, aged 36 at onset in the spring of 1911, suffered a recurrence in April of the following year. In May, 1913, while she was pregnant, she had a mild recurrence of pellagra. The record of this case for 1914 is incomplete.

Pellagrin 604 had her initial attack in the spring of 1911, when 37 years of age. She escaped recurrence in 1912 and also in 1913, in which year she gave birth to a daughter in May. In 1914 she suffered a mild recurrence of pellagra in June.

Pellagrin 212, aged 40 at onset in May, 1911, was pregnant throughout the spring and summer months of 1912. She escaped recurrence during that year and remained entirely free from symptoms in 1913 and 1914.

Pellagrin 278 was 40 years of age when she suffered her initial attack in July, 1911. She had recurrences in 1912 and 1913. In January, 1914, she became pregnant and remained free from symptoms to to our last observation, July $20,1914$.

Of the twenty-two instances of pregnancy subsequent to onset of pellagra in 1911, three terminated in the early part of the year, seven in the summer, eleven in the fall and for one the season was not recorded. In all three of the instances of childbirth in the early part of the year the patient remained free from symptoms of pellagra during the period of pregnancy; in four of the seven instances of termination in the summer mild recurrences were suffered late in pregnancy; of the eleven instances of childbirth in the fall, there were 
two with summer recurrence during pregnancy, one mild and one pronounced, while nine were free from symptoms.

Among the white pellagrins incident in 1911 there were three who were pregnant at the time of onset of pellagra. For these three instances of childbirth subsequent to onset, as well as for the twentytwo instances of pregnancy subsequent to onset cited above, the history of the mother in the three months following delivery may be considered. Of these twenty-five instances of childbirth, four occurred in the early months of the year and for only one of these was there history of recurrence of pellagra within three months. Of the nine instances of childbirth in the summer, only three were followed by recurrence within three months. Of the eleven instances of a delivery in the fall months, nine were recorded as free from symptoms in the months immediately following, while for two 1914 cases the records were incomplete because our field observations ceased in the fall of that year.

There were sixteen white pellagrins who suffered their initial attack in 1912 and whose records of childbirth or of pregnancy in subsequent years are sufficiently definite to be utilized in this discussion.

Pellagrin 593 was 16 years old at the time of onset in August, 1912. She was pregnant throughout the spring and summer months of 1913, giving birth to a child in August, 1913. She escaped recurrence in 1913, but suffered a mild attack of pellagra in 1914 .

Pellagrin 55 had her initial attack in June, 1912, when 19 years of age. She remained free from symptoms of pellagra in 1913, during which year she was pregnant from April. Her history for 1914 is incomplete.

For history of Pellagrin 280 see section on Initial Attack During Pregnancy.

Pellagrin 596 gave birth to a child in December, 1911. The following spring (1912) when she was 19 years old, her first attack of pellagra developed. She suffered a recurrence of the disease in 1913. In February, 1914, she became pregnant again and remained free from symptoms of pellagra for the year 1914 to our last observation in June.

Pellagrin 884 suffered her initial attack of the disease in the summer of 1912, when she was 20 years of age. The following summer she had a severe recurrence of pellagra. She became pregnant in June, 1913. The childbirth in March, 1914, was followed by a severe recurrence of symptoms in May.

Pellagrin 562, aged 23 at onset, suffered her initial attack of the disease in the spring of 1912, the exact month of onset being unrecorded. In April, 1912, she became pregnant, giving birth to a child the following December. She had a recurrence of pellagrous symptoms in May, 1913. In 1914, however, she was pregnant until well into July and remained free from symptoms up to the time of our last observation in the early part of July, 1914.

Pellagrin 102 was 24 years of age when she had her initial attack in May, 1912. She remained quite free from symptoms in 1913. In March, 1914, she became pregnant and had also escaped recurrence in that year to the date of our last observation, in October, 1914.

Pellagrin 833, aged 26 at onset in April, 1912, became pregnant in November of the same year. In May, 1913, while she was still pregnant, a mild recurrence of pellagra developed. She suffered recurrence also in 1914.

Pellagrin 614, aged 27 at onset, suffered her first attack in September, 1912, 
shortly after the birth of a child. In 1913 and 1914 she had complete but mild recurrences. In 1914 the symptoms appeared in March, when she was five months pregnant.

For history of Pellagrin 531 see section on Initial Attack During Pregnancy.

Pellagrin 164, aged 30, gave birth to a child in April, 1912. Pellagrous symptoms developed for the first time in the following June. She became pregnant again in June, 1913, giving birth to a child in February, 1914. She remained free from recurrence during 1913 and 1914.

For history of Pellagrin 701 see section on Initial Attack During Pregnancy.

Pellagrin 439 suffered her initial attack in April, 1912, at the age of 32 years. She had a recurrence of symptoms in April, 1913. Through the spring and early summer of 1914 she was pregnant and escaped recurrence during that year to our last observation, May 25, 1914.

Pellagrin 721, aged 32 at time of onset, suffered her initial attack in 1912, the exact month being unrecorded. She became pregnant in July, 1912, and gave birth to a child in April, 1913. In September of the same year she suffered a recurrence, but remained free from symptoms up to the time of our last observation in May, 1914.

For history of Pellagrin 253 see section on Initial Attack During Pregnancy.

Pellagrin 813, aged 35 at time of onset in 1912, became pregnant in February, 1913, and suffered a mild recurrence the following summer. For 1914 the record of this case is uncertain.

There were, therefore, eleven instances of pregnancy subsequent to onset of pellagra among white women with initial attack in 1912 . Of these, two terminated in the early part of the year, in one instance of which there was no recurrence of symptoms, while the history in the other was indefinite. There were five instances of pregnancy with termination in the summer, in three of which the patient remained quite free from symptoms, while in the other two, mild recurrences of pellagra appeared during pregnancy. Of the four instances of termination in the fall, the patient remained free from symptoms in three, while in the fourth instance a mild recurrence appeared during pregnancy in the summer.

Among the white pellagrins incident in 1912 there were four with initial attack during a pregnancy and two with subsequent childbirth, but for whom the onset month was indefinite. These six cases of childbirth following onset may be added to the eleven instances of pregnancy subsequent to onset, giving seventeen instances of childbirth subsequent to onset of pellagra. Of these, five occurred in 1914 too late for subsequent observation in our field work, which terminated in the fall of that year. Of the remaining twelve instances of childbirth, six occurred in the early part of the year, a recurrence followings within three months in three, while in the other three cases the mother remained quite free from symptoms. In three instances the childbirth occurred in the summer and in each case the mother escaped recurrence of symptoms in the three months immediately following. The three remaining instances of delivery occurred in the fall, the mother remaining free from recurrence for three months subsequent in each case. 
Of the white pellagrins who suffered an initial attack in 1913, there are eleven with definite record of pregnancy or of a childbirth subsequent to onset.

Pellagrin 613 was 21 years old when she suffered her initial attack of pellagra in 1913. She was pregnant during the spring and early summer of 1914, being delivered prematurely in July. In this case the delivery at the seventh month of pregnancy did not seem to lessen her apparent resistance to attack during that year, for she remained quite free from symptoms of pellagra up to our last observation, July 20, 1914.

For history of Pellagrin 1167 see section on Initial Attack During Pregnancy.

Pellagrin 600, aged 26 at onset in July, 1913, became pregnant late in the fall. In 1914 she remained free from recurrence during the period of pregnancy. After giving birth to twins in July, she suffered a mild recurrence of pellagra in August.

Pellagrin 873 was 27 years of age when she had her initial attack in 1913, the exact month of onset being unrecorded. In the spring of the same year she became pregnant, giving birth to a child in January, 1914. In April, 1914, she suffered a recurrence of symptoms.

Pellagrin 498, aged 28 at onset, gave birth to a child about three months before the pellagrous symptoms first appeared in 1913. In January, 1914, she again became pregnant and remained quite free from recurrence for that year to the date of the last observation, Sept. 12, 1914.

Pellagrin 997 had her first attack in July, 1913, when 29 years of age. She became pregnant in February, 1914, and remained free from symptoms for that year to the date of the last observation, July 20, 1914.

Pellagrin 537, aged 29 at the time of onset in March, 1913, had been in poor health following her last confinement in October, 1912. In January, 1914, she again became pregnant and escaped recurrence of pellagrous symptoms during 1914 to the date of our last observation, Sept. 2, 1914.

Pellagrin 450 suffered her initial attack in the spring of 1913, when 30 years of age. In 1914 she was pregnant and remained quite free from symptoms up to the last observation in June.

Pellagrin 1207, aged 31 at the time of onset in 1913, became pregnant in the latter part of that year and gave birth to a child in June, 1914. She, however, did not escape pellagrous symptoms in 1914, and suffered a mild recurrence in the spring, while still pregnant.

Pellagrin 889 suffered her first attack in May, 1913, when 31 years of age. One week after the birth of a daughter in April, 1914, she suffered a recurrence of pellagra.

Pellagrin 518, aged 39 at the time of onset in February, 1913, remained free from symptoms in 1914 . She was pregnant during the greater part of the pellagra season, giving birth to a child in June or July, 1914.

For histories of Pellagrins 1267 and 964, with onset in 1914, see section on Initial Attack During Pregnancy.

Among the white pellagrins with initial attack in 1913 there were, therefore, nine instances of subsequent pregnancy, of which one terminated in the spring, five in the summer and three in the fall. In the case of the pregnancy with termination in the spring the patient remained entirely free from symptoms of pellagra during the period of gestation. Of the five pregnancies with childbirth in the summer, there was entire freedom from symptoms in four, while in the fifth a mild recurrence of pellagra appeared in the seventh month. For the 
three pregnancies with termination in the fall there was apparently complete freedom from symptoms of pellagra during pregnancy.

There was one instance of onset during pregnancy in 1914 and one of uncertain onset date with subsequent childbirth. Adding these two cases of childbirth subsequent to onset to the foregoing nine instances of pregnancy following onset, we have eleven instances of childbirth subsequent to initial attack of pellagra for consideration. Six of these instances of childbirth occurred in 1914, too late for subsequent observations. Of the remaining five, two occurred in the early months of the year, with recurrence of pellagra following in each case; and the other three took place in the summer, a recurrence following in one case, while in the other two the mother escaped recurrence in the three months immediately following.

Among the white pellagrins with initial attack previous to 1915 , there were, therefore, eighty-two instances of pregnancy subsequent to onset and eighty-five instances of childbirth after onset of pellagra.

Of the colored pellagrins who suffered the initial attack previous to 1915 , there are only four with definite history of pregnancy or childbirth subsequent to onset.

Pellagrin 109 had her first attack in June, 1911, when she was 29 years old. A childbirth in April, 1912, was followed by puerperal fever, and in May the pellagrous symptoms again appeared. A second childbirth in the summer of 1913 was likewise followed by a recurrence of pellagra, of which the patient died in the fall of 1913.

Pellagrin 67, aged 15 at the time of onset in May, 1912, gave birth to an illegitimate child in May, 1913, and suffered a severe recurrence of pellagra, which appeared before accouchement and persisted for several weeks afterward. In 1914 she had another severe recurrence of pellagra of which she died in June, 1914.

Pellagrin 183 was 17 years old at the time of onset of pellagra in June, 1912. She was pregnant during the spring and summer of 1913 and gave birth to a child on Sept. 18, 1913. During 1913 she remained free from recurrence of the disease. She is without record for 1914.

Pellagrin 733, aged 27 at onset of pellagra in 1913, gave birth to a child on May 20, 1914, and appears, from her record, to have remained free from recurrence during that year.

There are in this small group five instances of pregnancy subsequent to onset among colored pellagrins, one terminating in the spring, three in the summer and one in the fall. In four instances the patient remained quite free from symptoms during the period of gestation; in the fifth case a severe recurrence was suffered late in pregnancy and the symptoms persisted after the birth of the child in May. For four of these five instances of pregnancy there is history during the months subsequent to delivery. In one 1914 case further data are not available. Recurrence within three months appeared after the two childbirths which occurred in the spring and summer, respectively. In the case of one summer childbirth, symptoms which had appeared 
during pregnancy persisted for several weeks afterward. For the instance of delivery in the fall there was no record of recurrence within three subsequent months.

In the records of all these pellagrins there were eighty-seven instances of pregnancy beginning subsequent to onset of pellagra and there were eighty-eight instances of childbirth taking place subsequent to the initial attack of the disease. The instances in these two categories are not equal in number, because the first contains sixteen ${ }^{7}$ instances of pregnancy during 1914 for which there are no records for the months following childbirth, and which, therefore, cannot be utilized in the second category. Moreover, the second group includes not only fifteen of the twenty cases of onset during pregnancy for which there is history subsequent to delivery, but also four cases in which it is uncertain whether the initial attack occurred before or during pregnancy, but for which subsequent history of childbirth and puerperium is available. Furthermore, two instances of pregnancy with recurrence can be utilized in the first category, but must be omitted from the second, since the recurrent pellagrous symptoms persisted for many weeks after delivery in each case.

RELATION OF PREGNANCY TO RECURRENT PELLAGRA

Those patients who survived the initial attack of pellagra present definite records of eighty-seven instances of pregnancy subsequent to the onset of pellagra. Eighty-two of these pregnancies occurred in white women. In three of these the record in regard to recurrence of pellagra is uncertain. In seventeen of the remaining seventy-nine instances, or 21.5 per cent., a recurrent attack of pellagra appeared during the pregnancy, while in sixty-two instances, or 78.5 per cent., the disease did not recur during pregnancy. The colored race presents five instances of pregnancy, a recurrence of pellagra appearing during pregnancy in only one instance, 20.0 per cent. of the five. Table 6 shows a summary of these observations. It is at once evident that the pregnant pellagrins have been very much less liable to recurrence than pellagrous women in general, for whom, as was shown in the preceding paper of this series, the annual recurrence rate was 63 per cent.

The data in regard to the eighteen recurrences of pellagra during pregnancy are summarized in Table 7 . In these eighteen recurrences there was not one instance of death from pellagra during the period of pregnancy. In one case, however, the mother died of pellagra shortly after the birth of her child. In three other cases the attack was

7. For ten of these instances of pregnancy in 1914 no recurrence was recorded to the date of the last observation late in the respective period. We feel justified, therefore, in utilizing these in the pregnancy group. 
Table 6.-Behavior During Pregnancy of Pellagrins Who Had Previously Suffered the Initial Attack

\begin{tabular}{|c|c|c|c|c|c|c|c|}
\hline \multirow{2}{*}{ Race } & \multirow{2}{*}{$\begin{array}{l}\text { Record } \\
\text { Uncertain }\end{array}$} & \multirow{2}{*}{$\begin{array}{l}\text { Record } \\
\text { Definite }\end{array}$} & \multicolumn{2}{|c|}{$\begin{array}{c}\text { Recurrent } \\
\text { Attacks }\end{array}$} & \multicolumn{2}{|c|}{$\begin{array}{l}\text { Escapes from } \\
\text { Recurrence }\end{array}$} & \multirow{2}{*}{ Total } \\
\hline & & & Number & Per Cent. & Number & Per Cent. & \\
\hline White.... & 3 & $79^{*}$ & 17 & 21.5 & 62 & 78.5 & $82^{*}$ \\
\hline Colored....... & 0 & $\mathbf{5}$ & 1 & 20.0 & 4 & 80.0 & 5 \\
\hline Total....... & 3 & $84^{*}$ & 18 & 21.4 & 66 & 78.6 & $8^{* *}$ \\
\hline
\end{tabular}

* This number ineludes ten pregnancies in 1914 in which no recurrences were noted to the date of the last observation.

TABle 7.-Summary of the Eighteen Recurrent Attacks of Pellagra Which Occurred During Pregnancy

\begin{tabular}{c|c|c|c|c|c}
\hline \hline $\begin{array}{c}\text { Pellagrin } \\
\text { Number }\end{array}$ & $\begin{array}{c}\text { Age at } \\
\text { Recurrence }\end{array}$ & $\begin{array}{c}\text { Date of } \\
\text { Recurrence }\end{array}$ & $\begin{array}{c}\text { Month of } \\
\text { Pregnancy }\end{array}$ & $\begin{array}{c}\text { Character of } \\
\text { Attack }\end{array}$ & $\begin{array}{c}\text { History During } \\
\text { Pregnancy }\end{array}$ \\
\hline 987 & 26 & Spring, 1909 & Late & Mild & Recovery \\
987 & 29 & Spring, 1912 & Early & Mild & Recovery \\
80 & 28 & July, 1911 & Eighth & Mild & Recovery* \\
824 & 18 & 1911 & Early & Mild & Recovery \\
275 & 21 & June, 1913 & Fourth & Mild & Recovery \\
112 & 27 & April, 1913 & Sixth & Mild & Recovery \\
860 & 36 & February, 1914 & Eighth & Severe & Persisted \\
896 & 20 & April, 1912 & Eighth & Mild & Recovery \\
62 & 23 & Summer, 1913 & Middle & Severe & Recovery \\
269 & 25 & May, 1913 & Seventh & Slight & Recovery \\
726 & 28 & June, 1914 & Ninth & Mild & Recovery \\
1033 & 29 & April, 1913 & Eighth & Mild & Recovery \\
565 & 38 & May, 1913 & Seventh & Mild & Recovery \\
833 & 27 & May, 1913 & Seventh & Mild & Recovery \\
614 & 29 & March, 1914 & Fifth & Mild & Recovery \\
813 & 36 & Summer, 1913 & Late & Slight & Recovery \\
1207 & 32 & April, 1914 & Seventh & Mild & Recovery \\
67 & 16 & Spring, 1913 & Late & Severe & Persistedt \\
\hline
\end{tabular}

* Some weeks after childbirth in August, the erythema reappeared on the hands.

$t$ The attack of pellagra persisted after the birth of her child and the patient died of pellagra in June, 1914.

t The attack of pellagra appeared before childbirth and persisted for a considerable time afterward, with recovery. The patient died in a subsequent recurrence of pellagra in June, 1914. 
undoubtedly severe, although followed by complete recovery for that year. One of these three patients, Pellagrin 80, gave a history of only the one recurrence after her initial attack in 1909 . In the case of another, Pellagrin 62, the disease recurred regularly each year after onset in 1911; while in the case of the third, Pellagrin 67, a colored woman, the second recurrence in the year following the childbirth ended in death. There remain fourteen instances, or 77.8 per cent. of the total number of recurrences during pregnancy, in which the attack of pellagra was mild.

Table 8.-Distribution of Recurrences of Pellagra During Pregnancy According to Month of Gestation

\begin{tabular}{l|c|c|ccc|c|c|c|c|cc}
\hline \\
\hline
\end{tabular}

The distribution of the recurrent attacks according to the month of gestation is shown in Table 8 . The bulk of the attacks of pellagra appeared after the sixth month. Furthermore, the three severe attacks observed are recorded as occurring in the middle of the period of

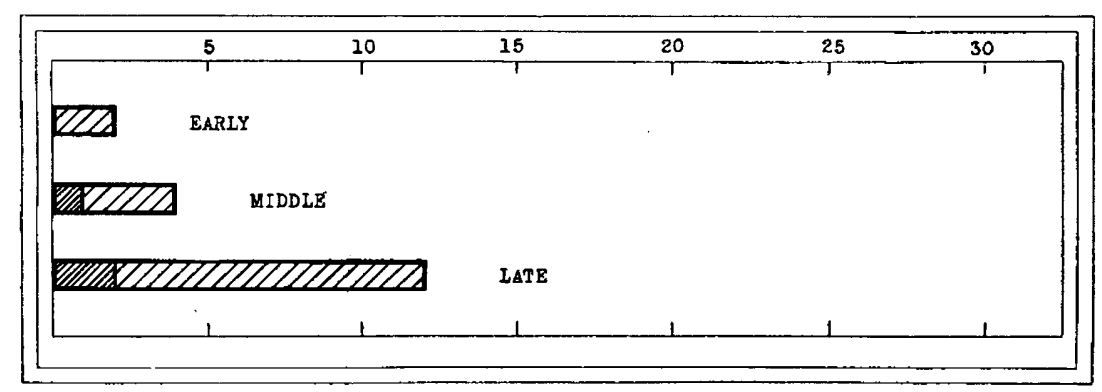

Fig. 3.-Recurrent attacks of pellagra during the first, second and last three months of pregnancy. The total length of the bar indicates the number of instances of recurrence beginning in the respective three-month period. The more thickly shaded portion indicates the number of instances in which the attack of pellagra was severe.

gestation, late in pregnancy and in the eighth month of pregnancy, respectively. It would appear, therefore, that the protective influence of pregnancy is greater in the earlier months.

In Table 9 the eighty-seven instances of pregnancy in pellagrins are summarized according to the season of the year in which the pregnancy terminated or was expected to terminate. From this tabulation it is evident that the season of the year plays a part in determining whether recurrence of pellagra shall take place during pregnancy. 
TABle 9.-Behavior of Pellagrous Women in Respect to Recurrence of Pellagra During Pregnancy of Pellagrins Whose Pregnancies Terminated Jn Different Seasons

\begin{tabular}{|c|c|c|c|c|c|c|}
\hline \multirow{2}{*}{$\begin{array}{l}\text { Behavior } \\
\text { during } \\
\text { Pregnaney }\end{array}$} & \multicolumn{2}{|c|}{ White Women } & \multicolumn{2}{|c|}{ Colored Women } & \multicolumn{2}{|c|}{ Both Races } \\
\hline & Number & Per Cent. & Number & Per Cent. & Number & Per Cent. \\
\hline
\end{tabular}

With pregnaney terminating from January to April, inclusive

\begin{tabular}{|c|c|c|c|c|c|c|}
\hline Recurrence................ & 1 & 6.3 & $\mathbf{0}$ & 0.0 & 1 & 5.9 \\
\hline No recurrence............. & 15 & 93.7 & 1 & 100.0 & 16 & 94.1 \\
\hline Total definite.............. & 16 & 100.0 & 1 & 100.0 & 17 & 100.0 \\
\hline Uncertain.................. & 2 & $\cdots \cdots$ & $\mathbf{0}$ & $\cdots \cdots$ & 2 & $\cdots \cdots$ \\
\hline Total................. & 18 & $\ldots \ldots$ & 1 & $\ldots$ & 19 & $\cdots$ \\
\hline
\end{tabular}

With pregnancy terminating from May to August, Inclusive

\begin{tabular}{|c|c|c|c|c|c|c|}
\hline Recurrence............... & 11 & 37.9 & 1 & 33.3 & 12 & 37.5 \\
\hline No recurrence............. & 18 & 62.1 & 2 & 66.7 & 20 & 62.5 \\
\hline Total definite............. & 29 & 100.0 & 3 & 100.0 & 32 & 100.0 \\
\hline Uncertain.................. & 0 & $\cdots \cdots$ & 0 & $\cdots \cdots$ & 0 & $\cdots \cdots$ \\
\hline Total.................. & 29 & $\ldots$. & 3 & .... & 32 & .... \\
\hline
\end{tabular}

With pregnancy terminating from September to December, inclusive

\begin{tabular}{|c|c|c|c|c|c|c|}
\hline Recurrence............. & 5 & 16.1 & 0 & 0.0 & 5 & 15.6 \\
\hline No recurrence............ & 26 & 83.9 & 1 & 100.0 & $2 ;$ & 84.4 \\
\hline Total definite............ & 31 & 100.0 & 1 & 100.0 & 32 & 100.0 \\
\hline Uncertain................ & 1 & $\cdots \cdots$ & 0 & $\cdots$ & 1 & $\cdots \cdots$ \\
\hline Total................. & 32 & $\ldots$ & 1 & $\cdots$ & 33 & $\ldots \ldots$ \\
\hline
\end{tabular}

With time of termination of pregnancy uncertain

\begin{tabular}{|c|c|c|c|c|c|c|}
\hline Recurrence............... & 0 & 0.0 & 0 & $\ldots .$. & 0 & 0.0 \\
\hline No recurrence.. & 3 & 100.0 & 0 & $\ldots$. & 3 & 100.0 \\
\hline Total definite.. & 3 & 100.0 & 0 & $\ldots \ldots$ & 3 & 100.0 \\
\hline Uncertain....... & 0 & $\ldots$. & 0 & $\ldots .$. & 0 & $\ldots$. \\
\hline Total.: & 3 & $\ldots .$. & 0 & $\ldots$. & 3 & $\ldots$. \\
\hline
\end{tabular}


When the pregnancy began in the early summer, namely, from April to July, inclusive, and terminated in the period from January to April, inclusive, recurrence of pellagra rarely appeared during the course of the pregnancy. This period, of course, corresponds with the nine months of the year in which onset of pellagra is least frequent in the general population. The pregnancies which began in the period August to November, inclusive, or, roughly, the autumn months, and terminated in the period from May to August, inclusive, showed the greatest frequency of recurrent attacks of pellagra, namely, 37.5 per cent. In these cases the later months of pregnancy coincided with those months of the year in which the attack of pellagra is most usually initiated in the general population, namely, April, May and June. The pregnancies of the third group began in the period from December to March, inclusive, or, roughly, the winter months, and terminated in

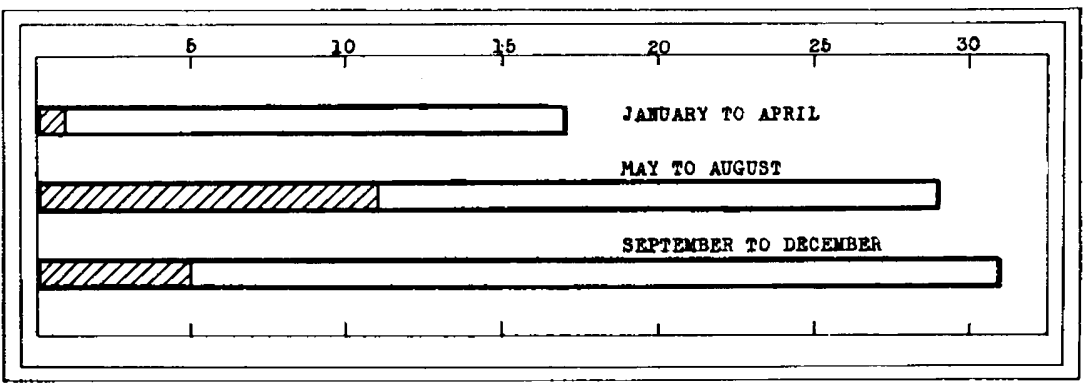

Fig. 4.--Recurrence of pellagra during pregnancy ending in different seasons. The number of instances of childbirth in each four-month period is indicated by the total length of the bar. The number of instances in each group in which recurrence of pellagra appeared during the period of gestation is indicated by the shaded portion of the respective bar.

the period September to December, inclusive. All of these pregnancies extended throughout the pellagra season. Nevertheless, in only 15.6 per cent. of them did recurrence of the disease appear during pregnancy. The months of greatest pellagra incidence, namely, April, May and June, here coincided with the earlier months of pregnancy rather than the later months, so that the low recurrence rate here supports the suggestion that the protective influence of pregnancy is more pronounced in the earlier rather than the later part of the period of gestation.

\section{RELATION OF CHILDBIRTH TO RECURRENT PELLAGRA}

There are eighty-eight instances of childbirth among pellagrins for whom there are records subsequent to the childbirth. The behavior during the three months following childbirth in these eighty-eight instances is summarized in Table 10. The frequency of recurrence in 
Table 10.-Behavior of Pellagrins During the Three Months Following ChildBirth

\begin{tabular}{|c|c|c|c|c|c|}
\hline \multirow{2}{*}{ Race } & \multicolumn{2}{|c|}{ Recurrent Attacks } & \multicolumn{2}{|c|}{ Escapes from Recurrences } & \multirow{2}{*}{ Total } \\
\hline & Number & Per Cent. & Number & Per Cent. & \\
\hline White..... & 21 & 24.7 & 64 & 75.3 & 85 \\
\hline Colored..... & 2 & 66.7 & 1 & 33.3 & 3 \\
\hline Total................ & 23 & 26.1 & 65 & 73.9 & 88 \\
\hline
\end{tabular}

TABle 11.-Behavior of Pellagrous Women in Respect to Recurrence of Pellagra During the Three Months Following Childbirth in Different Seasons

\begin{tabular}{|c|c|c|c|c|c|c|}
\hline \multirow{2}{*}{$\begin{array}{l}\text { Behavior } \\
\text { after } \\
\text { Childbirth }\end{array}$} & \multicolumn{2}{|c|}{ White Women } & \multicolumn{2}{|c|}{ Colored Women } & \multicolumn{2}{|c|}{ Both Races } \\
\hline & Number & Per Cent. & Number & Per Cent. & Number & Per Cent. \\
\hline
\end{tabular}

With childbirth occurring from January to April, inclusive

\begin{tabular}{r|c|r|r|r|r|r}
\hline $\begin{array}{r}\text { Recurrence................ } \\
\text { No recurrence.............. }\end{array}$ & 13 & 50.0 & 1 & 100.0 & 14 & 51.9 \\
& 13 & 50.0 & 0 & 0.0 & 13 & 48.1 \\
\hline Total..................... & 26 & 100.0 & 1 & 100.0 & 27 & 100.0 \\
\hline
\end{tabular}

With childbirth occurring from May to August, inclusive

\begin{tabular}{|c|c|c|c|c|c|c|}
\hline Recurrence............... & 7 & 25.0 & 1 & 100.0 & 8 & 27.6 \\
\hline No recurrence........ & 21 & 75.0 & 0 & 0.0 & 21 & 72.4 \\
\hline Total....... & 28 & 100.0 & 1 & 100.0 & 29 & 100.0 \\
\hline
\end{tabular}

With childbirth occurring from September to December, inclusive

\begin{tabular}{r|r|r|r|r|r|r}
\hline $\begin{array}{r}\text { Recurrence................ } \\
\text { No recurrence.............. }\end{array}$ & $\begin{array}{r}0 \\
28\end{array}$ & $\begin{array}{r}0.0 \\
100.0\end{array}$ & $\begin{array}{r}0 \\
1\end{array}$ & $\begin{array}{r}0.0 \\
100.0\end{array}$ & $\begin{array}{r}0 \\
29\end{array}$ & $\begin{array}{r}0.0 \\
100.0\end{array}$ \\
\hline Total.................. & 28 & 100.0 & $\mathbf{1}$ & 100.0 & 29 & 100.0 \\
\hline
\end{tabular}

With season of ehildbirth uncertain

\begin{tabular}{|c|c|c|c|c|c|c|}
\hline Recurrence... & 1 & 33.3 & 0 & $\ldots$. & 1 & 33.3 \\
\hline No recurrence... & 2 & 66.7 & 0 & $\cdots \cdots$ & 2 & 66.7 \\
\hline Total... & 3 & 100.0 & 0 & $\ldots$. & 3 & 100.0 \\
\hline
\end{tabular}


the first three months after childbirth, namely 26.1 per cent., is enormously high for a period of three months, just one quarter of a year. It may be compared with the annual recurrence rate of 63 per cent. for the total female pellagrins of Spartanburg County after dividing this latter figure by four, which yields a recurrence rate of 15.8 per cent. for a period of three months. It may also be compared with the recurrence rate during the nine months of pregnancy shown in the preceding section of this paper, namely, 21.4 per cent., after this latter figure has been divided by three, giving 7.1 per cent. as the recurrence rate for a period of three months. In comparison with either of these, the recurrence rate in the three months following childbirth, namely, 26.1 per cent., stands out conspicuously.

The behavior of these pellagrous women during the three months following childbirth is shown in Table 11, according to the season of the year in which the childbirth occurred. It is at once evident that

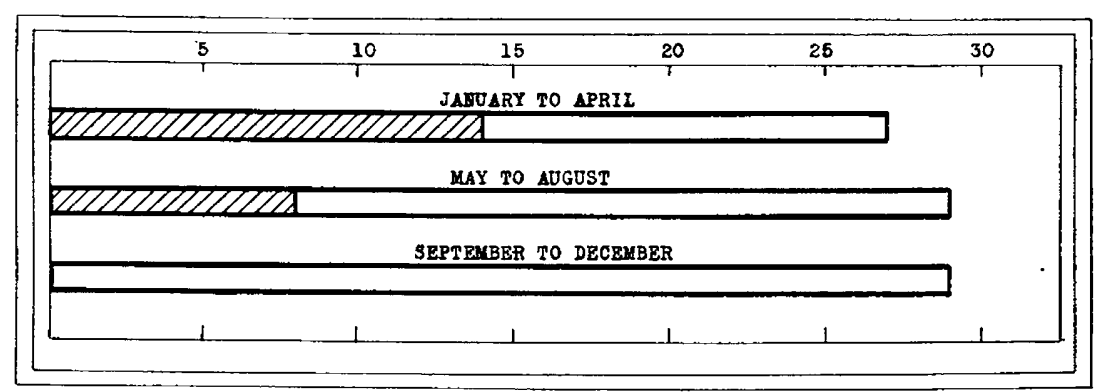

Fig. 5.-Recurrence of pellagra within three months following childbirth in different seasons. The number of instances of childbirth in each four-month period is indicated by the total length of the bar. The number of instances in which recurrence of pellagra appeared in the respective group within three months after childbirth is indicated by the shaded portion. Note that childbirth from September to December was not followed by recurrence of pellagra within three months in any instance.

the pellagrous women who bore children in the period from January to April, inclusive, most frequently suffered a recurrence of pellagra within three months. About one half of such childbirths were followed by recurrence of pellagra within this time. The childbirths in the period from May to August, inclusive, were followed by a recurrence of pellagra within three months in less than one third of the instances. On the other hand, the twenty-nine births which occurred in the period from September to December were not followed by recurrence of pellagra within three months in a single instance. It would appear, therefore, that childbirth does predispose to a recurrence of pellagra to a remarkable degree, but that this predisposing influence is not sufficient to determine recurrence of pellagra in the winter season. 
THE RELATION OF CHILDBEARING TO RECURRENCE OF PELLAGRA

In the foregoing sections it has been shown that in the population here studied, pregnancy has exercised an inhibitory influence on the recurrence of pellagra, while childbirth has predisposed to it. Inasmuch as gestation is normally accompanied by childbirth it would be of interest to know their combined influence in respect to recurrence of pellagra. If we add together the percentage of recurrences during the nine months of pregnancy, namely, 21.4, and the percentage of recurrences during the three months following childbirth, namely, 26.1 , we obtain a figure, 47.5 per cent., which is an appropriate measure of the recurrence rate for twelve months for puerperal women. This is somewhat lower than the annual recurrence rate for total female pellagrins in Spartanburg County, which was 63 per cent. The figures would indicate that puerperal women are less liable to recurrence of pellagra than other women. It is impossible to decide whether this apparent difference may be due directly to the physiologic exercise of the maternal function or may be merely correlated with it on account of the greater general vigor and superior environmental conditions which the childbearing woman is likely to enjoy. In any case the difference from the general recurrence rate is not very great. It would seem, however, to justify the conclusion that childbearing is not contraindicated in pellagrins, as one might suppose if only the frequency of recurrence following childbirth were taken into account.

The influence of season appears to be particularly important in this connection. The pellagrous women who bore children in the period from January to April, inclusive, suffered recurrence of the disease during pregnancy in 5.9 per cent. of instances and the analogous group suffered recurrence in the first three months after delivery in 51.9 per cent. of instances. The approximate frequency of recurrence for the twelve months beginning with pregnancy was, therefore, the sum of these figures, or 57.8 per cent., for this seasonal group. In the group with childbirth in the period from May to August, inclusive, the recurrence rate during pregnancy was 37.5 per cent. and the recurrence rate in the three months after delivery 27.6 per cent. The sum of these, or 65.1 per cent., represents approximately the recurrence rate for the year beginning with pregnancy, for this seasonal group. For the third seasonal group, in which childbirth occurred from September to December, inclusive, the recurrence rate during pregnancy was 15.6 per cent. and in the three months subsequent to delivery it was 0.0 per cent. The recurrence rate for the twelve months in this seasonal group is, therefore, approximately 15.6 per cent.

This indicated contrast is so marked that it seems worth while to present a separate tabulation, including as definite examples only those 
TABLE 12.-Behavior of Pellagrous Women in Respect to Recurrence of Pellagra During the Twelve Months Beginning with Conception, Summarized According to Season in Which Childbirth Occurred

\begin{tabular}{|c|c|c|c|c|c|c|}
\hline \multirow{2}{*}{$\begin{array}{l}\text { Behavior } \\
\text { after } \\
\text { Childbirth }\end{array}$} & \multicolumn{2}{|c|}{ White Women } & \multicolumn{2}{|c|}{ Colored Women } & \multicolumn{2}{|c|}{ Both Races } \\
\hline & Number & Per Cent. & Number & Per Oent. & Number & Per Cent. \\
\hline
\end{tabular}

With childbirth occurring from January to April, inclusive

\begin{tabular}{|c|c|c|c|c|c|c|}
\hline Recurrence............... & 10 & 58.8 & 1 & 100.0 & 11 & 61.1 \\
\hline No recurrence............. & 7 & 41.2 & 0 & 0.0 & 7 & 38.9 \\
\hline Total definite.............. & 17 & 100.0 & 1 & 100.0 & 18 & 100.0 \\
\hline Uncertain............... & 1 & $\ldots \ldots$ & 0 & $\ldots \ldots$ & 1 & ..... \\
\hline Total................. & 18 & $\cdots$ & 1 & $\ldots$ & 19 & $\ldots$ \\
\hline
\end{tabular}

With childbirth occurring from May to August, inclusive

\begin{tabular}{|c|c|c|c|c|c|c|}
\hline Recurrence................. & 16 & 64.0 & 2 & 100.0 & 18 & 66.7 \\
\hline No recurrence............. & 9 & 36.0 & 0 & 0.0 & 9 & 33.3 \\
\hline Total deflnite............... & 25 & 100.0 & 2 & 100.0 & 27 & 100.0 \\
\hline Uncertain.................. & 0 & $\cdots$ & 0 & $\cdots \cdots$ & 0 & $\ldots$ \\
\hline Total................. & 25 & $\cdots$ & 2 & $\cdots$ & 27 & $\ldots$. \\
\hline
\end{tabular}

With childbirth occurring from September to December, inclusive

\begin{tabular}{|c|c|c|c|c|c|c|}
\hline Recurrence............... & 5 & 22.7 & 0 & 0.0 & 5 & 21.7 \\
\hline No recurrence............ & 17 & 77.3 & 1 & 100.0 & 18 & 78.3 \\
\hline Total deflnite............ & 22 & 100.0 & 1 & 100.0 & 23 & 100.0 \\
\hline Uncertaln................ & 1 & .... & 0 & $\ldots$. & 1 & $\ldots$. \\
\hline Total................ & 23 & $\ldots$ & 1 & $\ldots$. & 24 & $\ldots$ \\
\hline
\end{tabular}

With season of childbirth not definitely recorded

\begin{tabular}{|c|c|c|c|c|c|c|}
\hline Recurrence................. & 1 & 33.3 & 0 & $\ldots \ldots$ & 1 & 33.3 \\
\hline No recurrence...... & 2 & 66.7 & 0 & $\ldots$. & 2 & 66.7 \\
\hline Total definite............. & 3 & 100.0 & 0 & $\cdots$ & 3 & 100.0 \\
\hline Uncertain................. & 0 & $\cdots \cdots$ & 0 & $\cdots$ & 0 & $\cdots \cdots$ \\
\hline Total.... & 3 & $\cdots$ & 0 & $\ldots$ & 3 & .... \\
\hline
\end{tabular}


instances in which the initial attack occurred previous to the pregnancy and in which there is available definite record for both the period of gestation and the three months following delivery. The figures are summarized in Table 12 . The differences between the three groups are here similar. Those women who bore children from September to December, inclusive, were only about one third as liable to recurrence during the twelve months including the whole period of pregnancy and the three months following childbirth as were the women who gave birth to children in other seasons of the year.

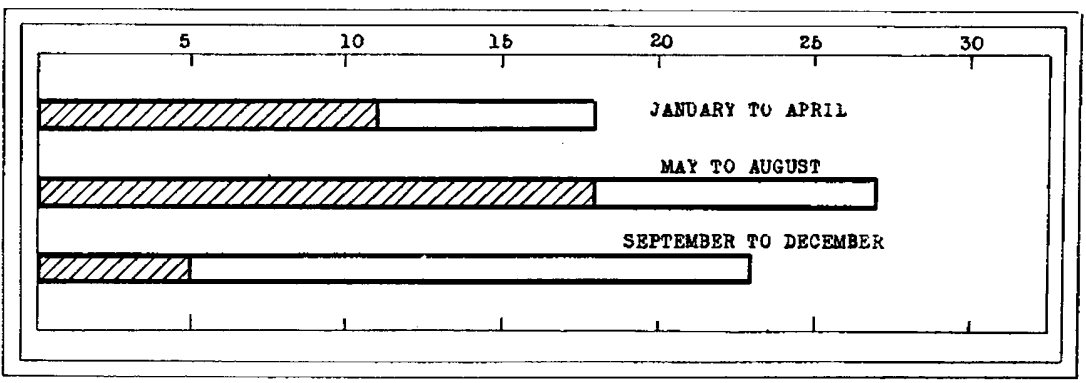

Fig. 6.-Recurrence of pellagra in childbearing women. The number of instances of childbirth in each four-month period is indicated by the total length of the bar. The number of instances in which recurrence of pellagra appeared during the twelve months, including the period of gestation and the three months following delivery, is indicated by the shaded portion. Note that only five of the twenty-three pellagrous women who gave birth to children from September to December suffered recurrence of pellagra during the twelve months.

This third group stands out in remarkable contrast to the other two groups in this respect, clearly indicating that the most favorable season for childbirth in this pellagrous population has been from September to December, inclusive. The contrast is so great that it might well be taken into account by those physicians who have pellagrous married women in their care.

\section{SUM MARY}

1. Twenty of the 624 initial attacks of pellagra in women in the age period 12 to 49 years, in Spartanburg County, occurred during pregnancy. This number represents 3.8 per cent. of 624 initial attacks in women of childbearing age and indicates that onset of pellagra has been relatively less frequent during pregnancy than at other times.

2. Sixteen of the 624 initial attacks, or 2.6 per cent., occurred in the month following childbirth, twenty-two, or 3.5 per cent. in the second and third months following childbirth and nineteen, or 3.0 per cent., in the fourth, fifth and sixth months following childbirth.

3. The proportion of initial attacks of pellagra in the six months 
subsequent to childbirth is distinctly excessive and the indicated increased liability to the development of pellagra is greater in the earlier months following this event.

4. Among eighty-seven instances of pregnancy in pellagrous women, in only eighteen, or 20.7 per cent., did a recurrent attack of pellagra appear during the period of gestation. This frequency is distinctly lower than the recurrence rate for pellagrous females in general, namely, 63 per cent. per year, and indicates a definitely increased resistance to recurrence of pellagra during pregnancy.

5. Recurrences of pellagra during pregnancy were less frequent in the earlier months. They were usually mild in character and no deaths occurred during the period of pregnancy.

6. In those pregnancies terminating from May to August, inclusive, recurrence of pellagra was relatively most frequent. In these instances the later months of gestation coincided with the season of greatest activity of pellagra.

7. Among eighty-eight instances of childbirth in pellagrous women there were twenty-three, or 26.1 per cent., in which a recurrence of pellagra appeared within three months after this event. This recurrence rate is enormously high in comparison with the normal rate of 15.8 per cent. for three months.

8. The influence of season was evidently of great importance. Childbirth in the period from September to December, inclusive, was not followed by recurrence of pellagra within three months in a single instance. Childbirth in other seasons, on the other hand, was followed by recurrence in about one third of the instances.

9. Considering the period of gestation and the three months following it together as a whole year, we see that recurrence has not been more frequent in childbearing women than for pellagrous women in general.

10. When considered in this way, the instances of pregnancy terminating in childbirth from September to December, inclusive, showed a very low frequency of recurrence for the whole year, namely, 21.7 per cent., which is about one third of the recurrence rate for pellagrous females in general.

11. On the other hand, in those pregnancies terminating during other seasons of the year the frequency of recurrence for the year was between 60 and 70 per cent.

12. These relations are believed to be of practical significance, not only for prognosis, but also as criteria to be utilized in the treatment and management of pellagrous married women. 